\title{
On the possible causes of recent increases in northern hemispheric total ozone from a statistical analysis of satellite data from 1979 to 2003
}

\author{
S. Dhomse ${ }^{1}$, M. Weber ${ }^{1}$, I. Wohltmann ${ }^{2}$, M. Rex ${ }^{2}$, and J. P. Burrows ${ }^{1}$ \\ ${ }^{1}$ Institute of Environmental Physics, University of Bremen, Bremen, Germany \\ ${ }^{2}$ Alfred Wegener Institute, Potsdam, Germany \\ Received: 9 August 2005 - Published in Atmos. Chem. Phys. Discuss.: 9 November 2005 \\ Revised: 7 February 2006 - Accepted: 8 February 2006 - Published: 13 April 2006
}

\begin{abstract}
Global total ozone measurements from various satellite instruments such as SBUV, TOMS, and GOME show an increase in zonal mean total ozone at northern hemispheric $(\mathrm{NH})$ mid to high latitudes since the mid-nineties. This increase could be expected from the peaking and start of decline in the effective stratospheric halogen loading, but the rather rapid increase observed in $\mathrm{NH}$ zonal mean total ozone suggests that another physical mechanism such as winter planetary wave activity has increased which has led to higher stratospheric Arctic temperatures. This has enhanced ozone transport into higher latitudes in recent years as part of the residual circulation and at the same time reduced the frequency of cold Arctic winters with enhanced polar ozone loss. Results from various multi-variate linear regression analyses using SBUV V8 total ozone with explanatory variables such as a linear trend or, alternatively, EESC (equivalent effective stratospheric chlorine) and on the other hand planetary wave driving (eddy heat flux) or, alternatively, polar ozone loss (PSC volume) in addition to proxies for stratospheric aerosol loading, QBO, and solar cycle, all considered to be main drivers for ozone variability, are presented. It is shown that the main contribution to the recent increase in $\mathrm{NH}$ total ozone is from the combined effect of rising tropospheric driven planetary wave activity associated with reduced polar ozone loss at high latitudes as well as increasing solar activity. This conclusion can be drawn regardless of the use of linear trend or EESC terms in our statistical model. It is also clear that more years of data will be needed to further improve our estimates of the relative contributions of the individual processes to decadal ozone variability. The question remains if the observed increase in planetary wave driving is
\end{abstract}

Correspondence to: S. Dhomse

(sandip@iup.physik.uni-bremen.de) part of natural decadal atmospheric variability or will persist. If the latter is the case, it could be interpreted as a possible signature of climate change.

\section{Introduction}

Long-term ozone observations at mid to high latitudes spanning several decades display both steady decline and high inter-annual and intra-annual variability. Figure 1 shows the monthly total ozone anomaly time series in the $50^{\circ} \mathrm{N}-60^{\circ} \mathrm{N}$ latitude band for different satellite data sets from 1979 to 2003: SBUV V8, merged TOMS/SBUV V8, and GOME WFDOAS V1 (1995-2003). Also shown in the figure are the annual mean total ozone for all data sets. It is evident that an increase in total ozone is observed in all data sets since about the mid-nineties following a steady decline during the eighties and early nineties (WMO, 1999). The effect of the Mount Pinatubo eruption in 1991 resulted in extremely low spring values for few years until 1994. The mid-nineties were also characterized by occurrences of several cold Arctic stratospheric winters with enhanced polar ozone losses (Pawson and Naujokat, 1999; WMO, 2003). After this period a steady rise in $\mathrm{NH}$ total ozone is observed. As an effect of higher total ozone in the late nineties, the long-term linear downward trend in ozone was reduced as compared to earlier studies (WMO, 2003). This paper tries to address the issue which physical and/or chemical processes may have contributed to the recent increase.

The main contributions to decadal ozone variability are changes in solar flux, ozone depleting substances, and ozone transport. In order to study long-term changes in ozone, it is necessary to separate the influence of various dynamical and

Published by Copernicus GmbH on behalf of the European Geosciences Union. 

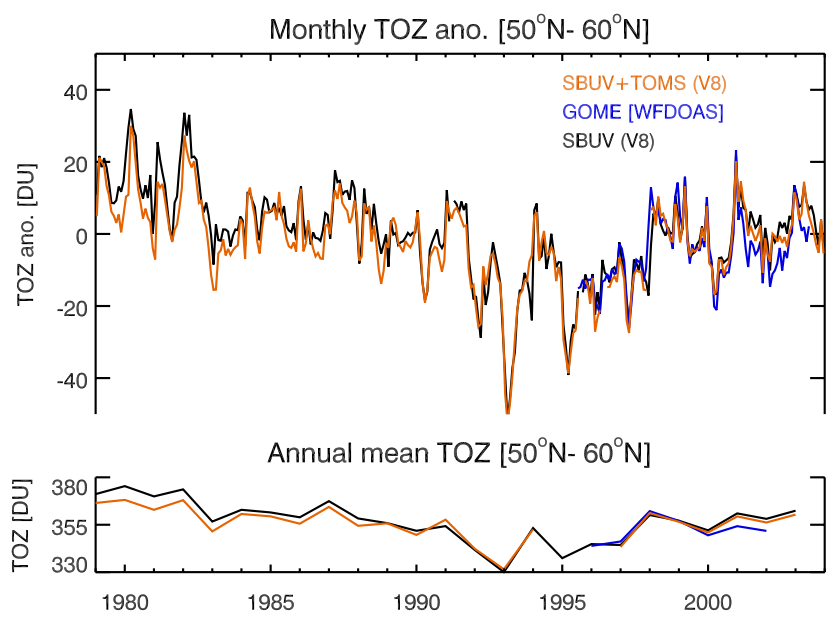

Fig. 1. Monthly mean zonal mean total ozone anomaly for $50^{\circ} \mathrm{N}-$ $60^{\circ} \mathrm{N}$ from different satellite data sets between 1979 and 2003 (Top). Annual mean total ozone is diplayed in the bottom panel. All satellite data show the increase in northern hemispheric total ozone at higher latitudes since 1995. Data from TOMS/SBUV V8 merged data set (orange), SBUV 8 (black), and GOME WFDOAS (blue) are shwon.

chemical processes as well as processes that act on shortand long-term time scales such as the quasi-biennial oscillation (QBO), El Niño/Southern Oscillation (ENSO or SOI) (SPARC, 1998; WMO, 2003), volcanic eruptions, heterogeneous chemical losses on the surface of polar stratospheric clouds (PSC), gas phase chemical losses, and tropospheric driven planetary wave activity which controls ozone transport into high latitudes as part of the wave driven residual circulation (Fusco and Salby, 1999).

In the following the relevant processes that are known to contribute to ozone variability are briefly summarized.

\subsection{Residual circulation and planetary wave driving}

The zonally averaged transport circulation in the wintertime stratosphere consists of a single mean meridional cell in each hemisphere with a rising branch in the tropics, poleward flow at mid-latitudes, and downward mass transport at higher latitudes. This circulation is driven by momentum deposited into the stratosphere by wave breaking (Andrews et al., 1987). Planetary waves propagate from the troposphere to the stratosphere, break at critical levels, and decelerate the mean zonal wind. Coriolis force and pressure gradient are not in equilibrium anymore and poleward motion sets in. The mass transport from the equator to the pole leads to adiabatic heating at high latitudes and drives stratospheric temperatures away from radiative equilibrium (Newman et al., 2001). Diabatic cooling sets in and leads to subsidence of air masses. This residual circulation tightly controls the wintertime ozone buildup at high latitudes (Fusco and Salby, 1999; Randel et al., 2002). It influences ozone in several ways: a stronger residual circulation means that more ozone is transported from its source region at the equator to higher latitudes, that meridional mixing is stronger, more ozone is transported downwards at high latitudes, where it is photochemically more stable, stratospheric temperatures rise, and less ozone is chemically depleted via heterogeneous reactions (Weber et al., 2003). The ability of waves to propagate vertically is dependent on the zonal mean flow and, therefore, wave activity is strongest in the winter of the respective hemisphere. The impact of the strength of the residual circulation of a given winter on the inter-annual ozone variability remains detectable until next autumn (Fioletov and Shepherd, 2003).

The magnitude of momentum transport from the troposphere into the stratosphere by planetary waves is presented by the divergence of Eliassen-Palm (EP) flux. The eddy heat flux $\overline{v^{\prime} T^{\prime}}$, which is directly proportional to the vertical component of Eliassen-Palm (EP) flux vector and approximately proportional to the EP flux divergence, is found to be a very attractive proxy for ozone transport. It determines the magnitude of the wave activity (Fusco and Salby, 1999; Newman et al., 2001; Weber et al., 2003). Other dynamical proxies such as Arctic Oscillation (AO) or North Atlantic Oscillation (NAO) index, polar jet strength index, polar stratospheric cloud (PSC) volume, $50 \mathrm{hPa}$ temperature are to some degree correlated with each other and can be linked to planetary wave activity (Randel and Cobb, 1994; Baldwin and Dunkerton, 1999; Chipperfield and Jones, 1999; Fusco and Salby, 1999; Randel et al., 2002; Salby and Callaghan, 2002; Plumb and Semeniuk, 2003; Steinbrecht et al., 2003).

\subsection{QBO}

The quasi-biennial oscillation of the equatorial zonal winds and temperatures has an obvious influence on the interannual variability of the tropical and subtropical ozone column (Baldwin et al., 2001). It mainly induces a secondary diabatic circulation which transports more or less ozone from the altitudes of photochemical production to the altitudes where ozone can be considered a conserved tracer (Reed, 1964). Typical amplitudes are 5-10 DU that are a considerable part of the inter-annual variability in the tropics. But the QBO has also been connected to ozone changes in mid-latitudes and even polar latitudes (Bowman, 1989; Lait et al., 1989; Chandra and Stolarski, 1991). The tropical signal is confined equatorward of about $15^{\circ}$ and has no seasonal dependence, while at higher latitudes the QBO response to ozone has largest amplitudes in winter and spring (Tung and Yang, 1994; Randel and Cobb, 1994; Baldwin et al., 2001). Possible reasons for the QBO influence in midlatitudes could be the modulation of the wave propagation in mid-latitudes, transport of equatorial anomalies to higher latitudes or changes in meridional mixing. The modulation of wave propagation is called the Holton-Tan effect (Holton and Tan, 1980). The influence on total ozone depends on both 
phase and strength of the QBO (WMO, 2003; Steinbrecht et al., 2003).

\subsection{Stratospheric halogen loading}

The impact of anthropogenically produced CFCs on ozone depletion has been widely studied since the early 1970s (Molina and Rowland, 1974; Stolarski and Cicerone, 1974; WMO, 2003). International measures to curb these emissions led to the introduction of the Montreal protocol (1987) and subsequent amendments to reduce emissions of chlorine and bromine containing species. The various halogen compounds have different potentials to deplete stratospheric ozone depending on their physical and chemical properties. EESC (equivalent effective stratospheric chlorine) is a quantity which is the sum of chlorine containing species multiplied by the number of $\mathrm{Cl}$ atoms contained in the compound and weighted by their fractional stratospheric release rate. It also accounts for the effect of bromine species (WMO, 2003). Like the stratospheric hydrogen chloride (Anderson et al., 2000), that is a measure of the total amount of chlorine in the upper stratosphere, the EESC has peaked in 1997 and started a slow decline afterward as displayed in Fig. 2.

\subsection{Heterogeneous chemistry}

Large ozone depletion has been regularly observed at high latitudes in late winter and early spring. It is caused by heterogenous chemistry on polar stratospheric clouds (PSCs) that activate large amounts of chlorine that catalytically destroy ozone inside the winter polar vortex (Solomon, 1999). This phenomenon is regularly observed in the southern hemisphere and is commonly known as the ozone hole (Farman et al., 1985). In contrast, large inter-annual variability in polar ozone loss is observed in the northern hemisphere. A high correlation between PSC volume integrated over the winter and the amount of polar vortex chemical ozone loss in the Arctic has been found (Rex et al., 2004). Long-term trends in polar ozone have also an impact on mid-latitude trends due to airmass mixing after the polar vortex break-up (Knudsen and Grooss, 2000; Fioletov and Shepherd, 2005).

\subsection{Solar variability}

Significant influences of solar variability on different meteorological quantities have been identified (Rind, 2002). The solar activity-ozone relationship has been taken into consideration in all international ozone trend assessments (WMO, 1999, 2003). The main support for this relationship are variations in the solar ultraviolet spectral irradiance that modify ozone production rates in the upper stratosphere (Brasseur, 1993). The secondary effect may include sudden increases in solar energetic particle precipitation causing short-term decreases in high altitude ozone concentration related to downward transport of $\mathrm{NO}_{\mathrm{y}}$ from the mesosphere down to the upper stratosphere (Jackman et al., 2000; Sinnhuber et al.,

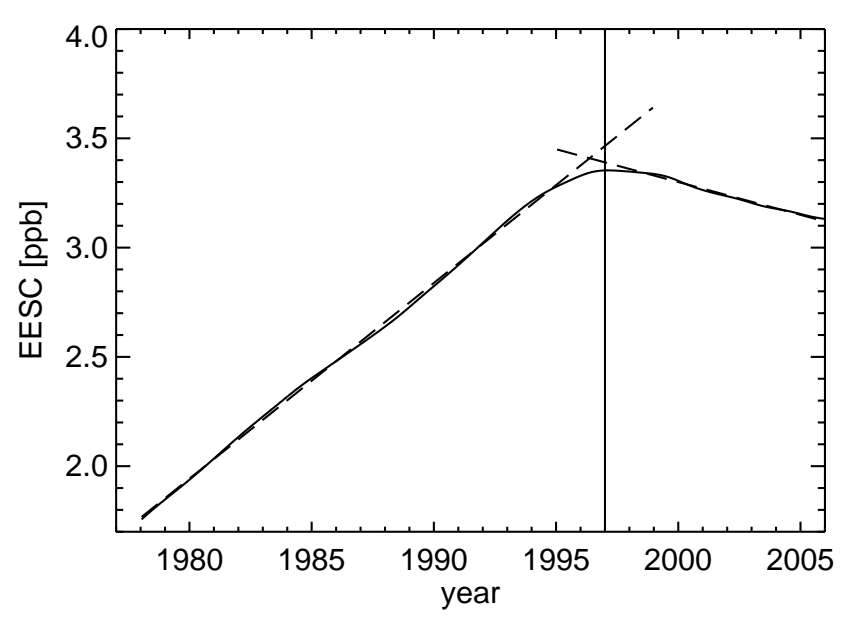

Fig. 2. Equivalent effective stratospheric chlorine loading (EESC) in ppb (WMO, 2003). The straight lines show linear fits to the inclining phase up to December 1995 (slope of $0.9 \mathrm{ppb} /$ decade) and to the slow decline after January 1999 (slope of $-0.3 \mathrm{ppb} /$ decade), respectively (dashed lines). A 9 DU/decade total ozone decrease during the first phase would correspond to a 3 DU/decade increase after 1999 if the ozone change is solely due and anti-correlated with EESC.

2003). There is evidence that indirect effects from solar activity influence lowermost stratospheric ozone via dynamical coupling (Labitzke and van Loon, 1993; Kodera and Kuroda, 2002). Analysis of various ground based and satellite records extending over 2-6 decades indicate the existence of decadal scale variation of total ozone that correlates with the solar cycle (Jackman et al., 1996; Miller et al., 1996; Hood et al., 1997; Zerefos et al., 1997; Ziemke et al., 1997; McCormack et al., 1997).

\subsection{Stratospheric aerosols}

Large enhancements in stratospheric aerosols were observed after major volcanic eruptions like El Chichón in 1982 (Hofmann and Solomon, 1989) and Mt. Pinatubo in 1991 (Parrish et al., 1998). Very low ozone values were observed following the Pinatubo event (Randel et al., 1995; Solomon et al., 1996) in the NH. A similar ozone deficit, however, was not observed in the southern hemisphere. Solomon et al. (1996) showed that major volcanic eruptions affect atmospheric dynamics and radiative forcing through scattering and absorption of solar radiation. They also showed that the occurrence of two major volcanic eruptions nine years apart during declining phases of solar cycles may lead to some confusion in separating volcanic and solar influence on ozone.

\subsection{El-Niño/southern oscillation}

ENSO is more or less a zonal phenomenon and normally leads to lower stratospheric temperature and total ozone anomalies that are opposite to the temperature anomalies in 


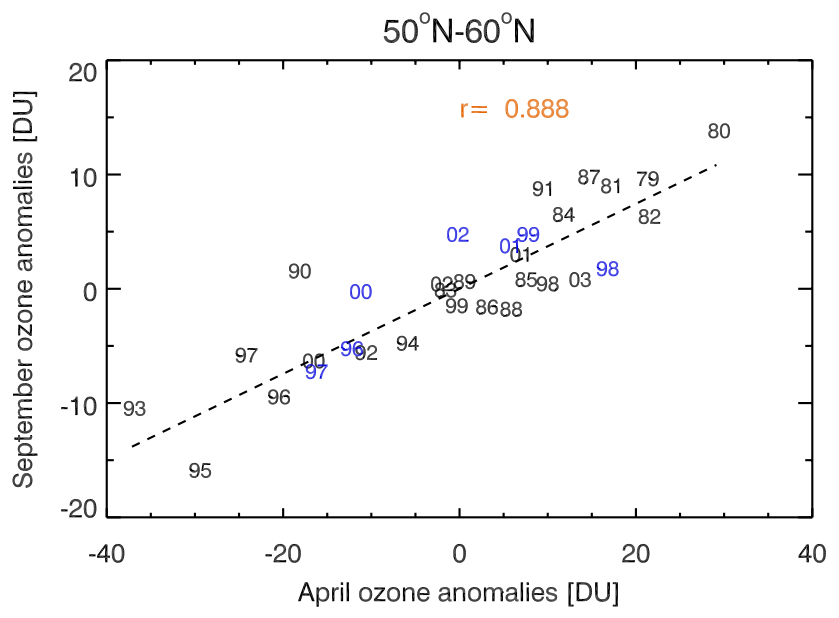

Fig. 3. Correlation of SBUV V8 total ozone anomaly in April with September anomalies between $50^{\circ} \mathrm{N}$ and $60^{\circ} \mathrm{N}$. High (low) ozone anomalies in spring lead to (low) high ozone anomalies in late summer. This relationship is valid for all summer months (Fioletov and Shepherd, 2003). Data in blue are anomalies obtained from GOME data.

the troposphere (Gettelman et al., 2001; Steinbrecht et al., 2003). The changes in ozone anomalies during strong El Niño and La Niña events may introduce additional variance and modify the ozone field (Shiotani, 1992; Zerefos et al., 1997; Logan et al., 2003).

\subsection{This work}

This paper presents a statistical analysis of twenty five years of total ozone data using various explanatory variables that represent physical and chemical processes that are known to modify the global ozone distribution as just briefly described above. Such analyses have been regularly applied to determine long-term trends in ozone (WMO, 1999, 2003). The major difference to other studies is that additional proxies such as PSC volume and eddy heat flux terms representing ozone chemistry and transport are added to better elucidate on the contribution of individual processes. This allows us to discuss the possible causes of the recently observed increase in middle to high latitude ozone and to quantify the contribution of the various processes to the inter-annual variability observed in the total ozone record.

In Sect. 2 the total ozone data sets from SBUV, SBUV/TOMS merged (both 1979-2003), and GOME (1995-2003) are briefly described, followed by a presentation of proxies for planetary wave driving (Sect. 3) and PSC volume (Sect. 4) that are used as explanatory variables standing for dynamical and chemical ozone processes. Other commonly used proxies, among them solar flux and QBO, are briefly described in Sect. 5. After briefly summarizing in Sect. 6 the regression model as applied to the SBUV total ozone data, the results are discussed in detail in Sect. 7 with major conclusions drawn in Sect. 8.

\section{Satellite ozone data}

Total column ozone data used in this study are SBUV V8 data from Nimbus 7 (January 1979-December 1989), NOAA11 (January 1990-December 1993, July 1997-December 2000), NOAA09 (January 1994-June 1997) and NOAA16 (January 2001-December 2003) (Barthia et al., 2004). The SBUV/TOMS V8 merged data set were obtained from Goddard Space Flight Center web site http://code916.gsfc. nasa.gov/Data_services/merged/mod_data.public.html (Frith et al., 2004). GOME total ozone data from 1995 to 2003 have been processed using the Weighting Function DOAS approach (Coldewey-Egbers et al., 2005; Weber et al., 2005). All data sets agree well with each other. From Fig. 1 it appears that the SBUV/TOMS merged data set as well as GOME show lower values than SBUV after about year 2000 and it is also lower during the earlier record. The positive bias in the SBUV data record with respect to TOMS was also found in the comparison with ground data (Labow et al., 2004). A big advantage of the SBUV data set is that the various data sets from Nimbus to NOAA16 show small differences during periods of overlapping missions and, thus, are well suited for long-term trend studies (Barthia et al., 2004; Labow et al., 2004). The comparison between data sets highlights the critical issue of maintaining long-term time series using multiple satellite data sets.

\section{Proxy for planetary wave driving}

We use the $100 \mathrm{hPa}$ eddy heat flux averaged over midlatitudes as a proxy for ozone transport due to variation in planetary wave driving. Monthly mean eddy heat fluxes at $100 \mathrm{hPa}$ are calculated using ECMWF 40 year reanalysis data (ERA-40) (Uppala et al., 2006) for the period of 1979-2001 and from operational data for the period 2002-2003 and have been area weighted and averaged between $45^{\circ} \mathrm{N}-75^{\circ} \mathrm{N}$.

Meridional ozone transport and mixing related to planetary wave driving is mainly confined to winter and spring. In late spring and summer total ozone changes are mainly controlled by $\mathrm{NO}_{\mathrm{x}}$ and photo-chemistry (Brühl et al., 1998). The photochemical lifetime does not vary from year to year (Randel et al., 2002), but initial conditions vary, e.g. winter anomalies due to variation in the buildup of ozone are still observed in late summer ozone anomalies (Fioletov and Shepherd, 2003) as shown in Fig. 3. To account for this combined dynamical effect of wintertime ozone buildup and persistent ozone anomalies in spring and summer, the cumulative eddy heat flux proxy for a given month of ozone observation is calculated by integrating the monthly eddy heat flux from last fall (October) to that month. For example, the October cumulative eddy heat flux is simply the monthly mean eddy heat flux from October, while for April, it is averaged from preceding October until April, and for September from 
preceding October until September. The cumulative eddy heat flux for a given month can be described as follows,

$h^{*}(m)=\frac{\int_{m^{\prime}=m_{0}}^{m} h\left(m^{\prime}\right) d m^{\prime}}{\int_{m^{\prime}=m_{0}}^{m} d m^{\prime}}$

with $m_{0}$ being the starting month (here October). Summer eddy heat fluxes are fairly small so that the main contribution to the cumulative eddy heat flux comes from the winter and early spring months.

Using GOME total ozone data and UKMO eddy heat flux data from the period 1996-2003, Weber et al. (2003) proved that a compact relationship between winter integrated eddy heat flux and the winter time ozone buildup exists. Figure 4 shows the ozone build-up for the $50^{\circ} \mathrm{N}-60^{\circ} \mathrm{N}$ latitude band during the last 25 years of SBUV data. Winter time ozone gain is calculated by subtracting the October total ozone value from the next year's April total ozone and it is correlated with the cumulative eddy heat flux from ERA40. For the period 1979-2003, correlation exceeds 0.56 and is statistically significant. As an effect from the Pinatubo eruption, ozone deviates from the regression line in winter 1992/93. For all late winter months (January to April) the correlations are quite significant for middle to high latitudes. Correlations are positive at high latitudes and are negative in the tropics.

In tropics $\left(<30^{\circ} \mathrm{N}\right)$ this cumulative effect from the planetary wave driving is short-lived due to the photochemical production of ozone. The approximate photochemical relaxation time is somewhere between one and three months at $25 \mathrm{~km}$ altitude in the tropics (see Fig. 2 in McLinden et al., 2000). An average of the two previous months is taken for the cumulative heat flux, e.g. for April, the mean between March and April is computed. From August to November (during $\mathrm{SH}$ winter/spring) the equivalent southern hemispheric two month eddy heat flux proxy, here averaged from $45^{\circ} \mathrm{S}$ to $75^{\circ} \mathrm{S}$, is included in the statistical model. The $\mathrm{NH}$ two month mean eddy heat flux is used from December until May in the tropics.

\section{PSC volume proxy}

The PSC volume is a suitable proxy for heterogenous chemical (i.e. polar) ozone loss (Solomon, 1999; Rex et al., 2004). It has been calculated from NCEP reanalysis data set by counting all grid points north of $60^{\circ} \mathrm{N}$ below the formation temperature of NAT (nitric acid trihydrate) and weighting them with their volume. NAT formation temperatures have been calculated according to Hanson and Mauersberger (1988) as a function of nitric acid mixing ratio, water vapor mixing ratio, and pressure. A constant water vapor profile of $5 \mathrm{ppm}$ and a nitric acid profile (Kleinböhl et al., 2003) of 5, $6,7,8,10,10,7$, and $5 \mathrm{ppb}$ for atmospheric pressures of 200 , $150,100,70,50,30,20$, and $10 \mathrm{hPa}$, respectively, have been

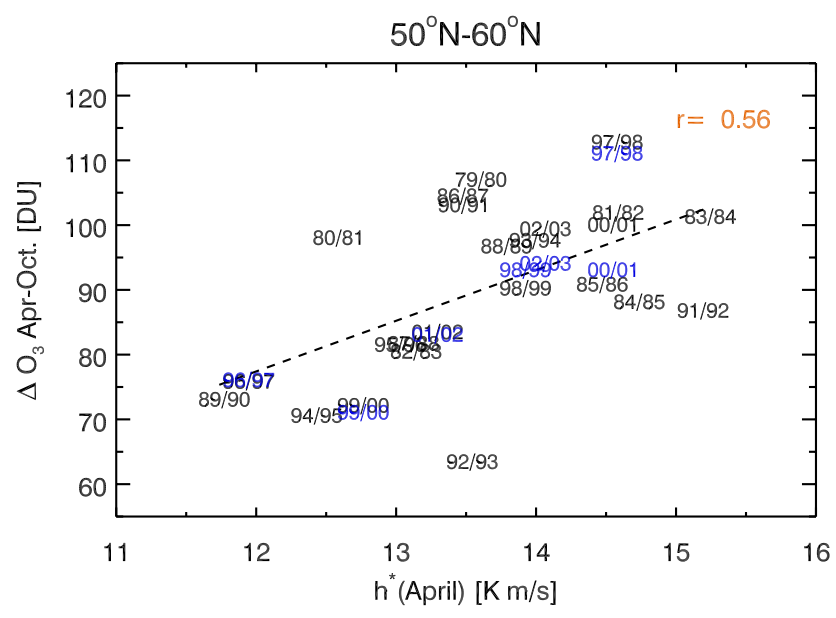

Fig. 4. Relationship between winter/spring ozone buildup (AprilOctober difference) at $50^{\circ} \mathrm{N}-60^{\circ} \mathrm{N}$ as a function of the accumulated eddy heat flux $h^{*}$ (April) as given by Eq. (1). Monthly mean zonal mean ozone are from SBUV V8. The effect of Pinatubo eruption can be clearly seen in 1992/93. Blue years indicate GOME values.

assumed. Monthly PSC volumes used in this study are integrated from the preceding October to the respective month of ozone observation. The proxy is set to zero for October and November since PSC volumes are negligibly small during these months. Stratospheric circulation is mainly zonal during winter and air is continuously processed over the winter months inside the polar vortex such that the ozone loss accumulates over winter and spring. In addition, the level of chlorine activation on PSC surfaces responsible for heterogenous chemical ozone loss depends also on the available inorganic chlorine and the PSC volume must be multiplied by the EESC. The modified polar ozone loss proxy is then defined as follows

$V_{p s c}^{*}(m)=\frac{\int_{m^{\prime}=m_{0}}^{m} \operatorname{EESC}\left(m^{\prime}\right) \cdot V_{p s c}\left(m^{\prime}\right) d m^{\prime}}{\int_{m^{\prime}=m_{0}}^{m} d m^{\prime}}$.

with $m_{o}$ being October. In the statistical regression either the PSC volume or eddy heat flux terms have been included.

\section{Other proxy data}

The southern oscillation index (SOI) is obtained from the Climate Prediction Center (CPC, http://www.cpc.ncep.noaa. gov/data/indices/). Both QBO indices at $30 \mathrm{hPa}$ and $10 \mathrm{hPa}$, respectively, are from The Free University Berlin (FUB) analysis (B. Naujokat, personal communication). Most of earlier regression models use QBO harmonics to account for time lags. We use QBO indices at $30 \mathrm{hPa}$ and $10 \mathrm{hPa}$, which are sufficient to adjust for both strength and phase of QBO. It also avoids the necessity to search for an optimum time lag for the fitting (Randel et al., 1995; Ziemke 
et al., 1997). The monthly stratospheric aerosol loading as a response to volcanic eruptions are from NASA Goddard Institute of Space Studies (http://www.giss.nasa. gov/data/strataer/), and are monthly mean aerosol optical depths at $550 \mathrm{~nm}$ (update from Sato et al., 1993). EESC concentration were obtained from the European Environment Agency web site http://www.eea.eu.int. For solar flux data we used the MgII index (ftp://ftp.ngdc.noaa.gov/STP/ SOLAR_DATA/SOLAR_UV/NOAAMgII_dat), which is a better proxy for UV solar flux variability than either F10.7 cm flux or sunspot number data (Viereck et al., 2001, 2004). The MgII index has been smoothed with a boxcar with five months full width in order to remove short term solar variability.

\section{Regression model for trend studies}

The regression model used in this study is quite similar to other regression models used in the past to study ozone trends (SPARC, 1998; Shindell et al., 1999a; WMO, 1999; Randel et al., 1999; Ziemke et al., 1997; Staehelin et al., 2001). It has been constructed as follows

$$
\begin{aligned}
\operatorname{TOZ}(n)= & \sum_{m=1}^{12} \alpha_{m}^{\circ} \cdot \delta_{m n}+\sum_{m=1}^{12} \alpha_{m}^{\mathrm{lin}} \cdot \delta_{m n} \cdot n \\
& +\sum_{m=1}^{12} \alpha_{m}^{h f} \cdot \delta_{m n} \cdot h^{*}(n) \\
& +\sum_{m=1}^{12} \alpha_{m}^{q b o 30} \cdot \delta_{m n} \cdot \mathrm{qbo} 30(n) \\
& +\sum_{m=1}^{12} \alpha_{m}^{q b o 10} \cdot \delta_{m n} \cdot \mathrm{qbo} 10(n) \\
& +\alpha^{\text {sol }} \cdot \operatorname{sol}(\mathrm{n})+\alpha^{S O I} \cdot \operatorname{SOI}(n) \\
& +\alpha^{\text {aeroc }} \cdot \operatorname{aeroc}(n) \\
& +\sum_{m=1}^{12} \alpha_{m}^{\text {aerop }} \cdot \delta_{m n} \cdot \operatorname{aerop}(n)+\epsilon(n)
\end{aligned}
$$

where $T O Z(n)$ is the monthly mean total ozone of month $n$, which is a running index from month zero to 299 covering the period 1979 to $2003, \alpha_{m}^{\circ}$ are monthly constants for the annual cycle $(m=1, \ldots, 12), \alpha_{m}^{\text {lin }}$ are monthly linear trend coefficients, $\alpha_{m}^{h f}$ are eddy heat flux contribution coefficients, $\alpha_{m}^{p s c}$, the heterogenous chemical loss coefficients (excluding October and November), $\alpha^{\text {sol }}$, coefficient for solar flux variability, $\alpha_{m}^{q b o 30}$ and $\alpha_{m}^{q b o 10}$, QBO coefficients at 30 and $10 \mathrm{hPa}$, respectively, $\alpha^{\mathrm{SOI}}$, the El Niño/ Southern Oscillation coefficient, and $\alpha^{\text {aeroc }}$ and $\alpha_{m}^{\text {aerop }}$, two stratospheric aerosol loading terms due to El Chichón and Pinatubo eruption, respectively. $\delta_{m n}$ is one when index $n$ corresponds to one of the months of a given year and otherwise zero. $\epsilon(n)$ represents the unexplained variance of the statistical model or, in short, the residual.

There are twelve monthly constants in our regression model and they account for the seasonal variation of ozone. The monthly linear trend terms or, alternatively, the EESC terms account for the contribution from gas phase chemical ozone loss (Zerefos et al., 1997). There are twelve eddy heat flux, PSC volume, QBO, and Pinatubo aerosol fitting parameters used in the regression model to separate the effects into individual months. The El Chichón stratospheric aerosol contribution turned out to be comparatively small so that a separation by individual months was not needed.

The linear trend term is traditionally associated with the gas phase chemical ozone loss as expected from the steady increase in stratospheric chlorine loading. As already discussed the EESC has started to decline after peaking in 1997 , so that a change from linear trend should be expected. We used both EESC and linear terms to elucidate the significance of the EESC in the total ozone time series. Linear trend terms have been replaced by corresponding EESC terms in some regression runs as follows:

$$
\sum_{m=1}^{12} \alpha_{m}^{\mathrm{lin}} \cdot \delta_{m n} \cdot n \longrightarrow \sum_{m=1}^{12} \alpha_{m}^{\mathrm{EESC}} \cdot \delta_{m n} \cdot \operatorname{EESC}(n)
$$

In some fits the eddy heat flux term has been replaced by the accumulated PSC volume proxies as follows:

$$
\sum_{m=1}^{12} \alpha_{m}^{h f} \cdot \delta_{m n} \cdot h^{*}(n) \longrightarrow \sum_{m=1}^{12} \alpha_{m}^{p s c} \cdot \delta_{m n} \cdot V^{*}(n)
$$

It was found that a simultaneous fit of eddy heat flux and PSC volume did not improve the fit significantly, in particular after applying the auto-regression corrections as described below. This is not unexpected since planetary wave driving, polar stratospheric temperatures (Newman et al., 2001), and chlorine activation (Weber et al., 2003) are linked. Implication of the exchange of these terms on the statistical fitting are investigated in the following section.

After applying the regression, the residuals $\epsilon(n)$ show non-negligible auto-correlation and this violates the assumption in the least-squares fitting with random (Gaussian distributed) noise in the data. It is a common practice to apply a Cochrane-Orcutt transformation to the regression equation using an estimate of the auto-correlation with time lag of one month (Cochrane and Orcutt, 1949; Tiao et al., 1990; Weatherhead et al., 1998; Plets and Vynckier, 2000; Bodeker et al., 1998; Reinsel et al., 2002). After fitting the transformed model, the remaining residuals should be normally distributed, otherwise this procedure has to be repeated as just described. Even though most of the fitting coefficients do not change much after the transformation, the parameter error nevertheless increases and this is important with regard to the judgment of statistical significance of individual processes. The occurrence of auto-correlation in the residuals may be due to either measurement errors, for instance 
time drift in observational data, due to uncertainties in the explanatory variables particularly with regard to the cumulative proxy data, or due to some missing processes which are not accounted for in our model. Most likely it is a combination of all three. In this study it sufficed to apply one Cochrane-Orcutt transformation to Eq. (3) to obtain an improved estimate of $\alpha \mathrm{s}$.

\section{Results}

Monthly mean zonal mean total ozone anomalies for the $50^{\circ} \mathrm{N}-60^{\circ} \mathrm{N}$ latitude band from TOMS/SBUV V8 merged, WFDOAS GOME, and SBUV V8 data sets are shown in Fig. 1. The regression model with linear trend terms has been only applied to SBUV V8 data and the reconstruction of monthly total ozone anomalies (after subtraction of the monthly constants) are shown in Fig. 5 for both $30^{\circ} \mathrm{N}-$ $40^{\circ} \mathrm{N}$ and $50^{\circ} \mathrm{N}-60^{\circ} \mathrm{N}$ bands. The ozone reconstruction with EESC terms replacing the linear trend terms is shown for the same latitude bands in Fig. 6. Both regression models with either linear or EESC terms show about the same significance in the overall fitting. The issue of linear versus EESC trend in the ozone reconstruction is discussed further down below. In general, the correlation between modeled and observed total ozone anomalies is in the range of 0.8 to 0.9 .

General features like the observed downward trend until the mid-nineties, significant ozone losses following Mount Pinatubo eruption, and increase in ozone after the midnineties are well captured in both ozone reconstructions. The contributions from individual explanatory variables have been added in Figs. 5 and 6 (top of each time series). Linear (EESC) and eddy heat flux terms are only plotted for April and September for better clarity.

The influence of the QBO on spring total ozone can be clearly seen in the $30^{\circ} \mathrm{N}-40^{\circ} \mathrm{N}$ latitude band (up to $20 \mathrm{DU}$ from easterly phase to westerly phase and vice versa) while at high latitudes it is somewhat smaller (about $10 \mathrm{DU})$. In the tropics (below $10^{\circ} \mathrm{N}$ ) the QBO influence is observed in all months, while its effect is limited to winter spring at higher latitudes. Linear terms (or EESC term) and eddy heat flux contributions increase with latitude. Aerosol loading terms associated with the Pinatubo eruption explain about a maximum decrease of $50-60 \mathrm{DU}$ in the $50^{\circ} \mathrm{N}-60^{\circ} \mathrm{N}$ latitude band and about $15-20 \mathrm{DU}$ at $30^{\circ} \mathrm{N}-40^{\circ} \mathrm{N}$ during winter/spring 1991/92. Solar flux cycle explains up to 15 DU ozone variability from solar maximum to solar minimum. At higher latitudes the eddy heat flux explains up to $20 \mathrm{DU}$ increase in ozone during dynamically active Arctic winters (e.g. mideighties and end of nineties).

Typical residuals from the regression analysis of Eq. (3) with linear trend terms at $30^{\circ} \mathrm{N}-40^{\circ} \mathrm{N}$ and $50^{\circ} \mathrm{N}-60^{\circ} \mathrm{N}$ are shown in Fig. 7, respectively. In these figures both residuals with (red) and without auto-regressive adjustment (black) are shown. Also indicated are the various satellite platforms
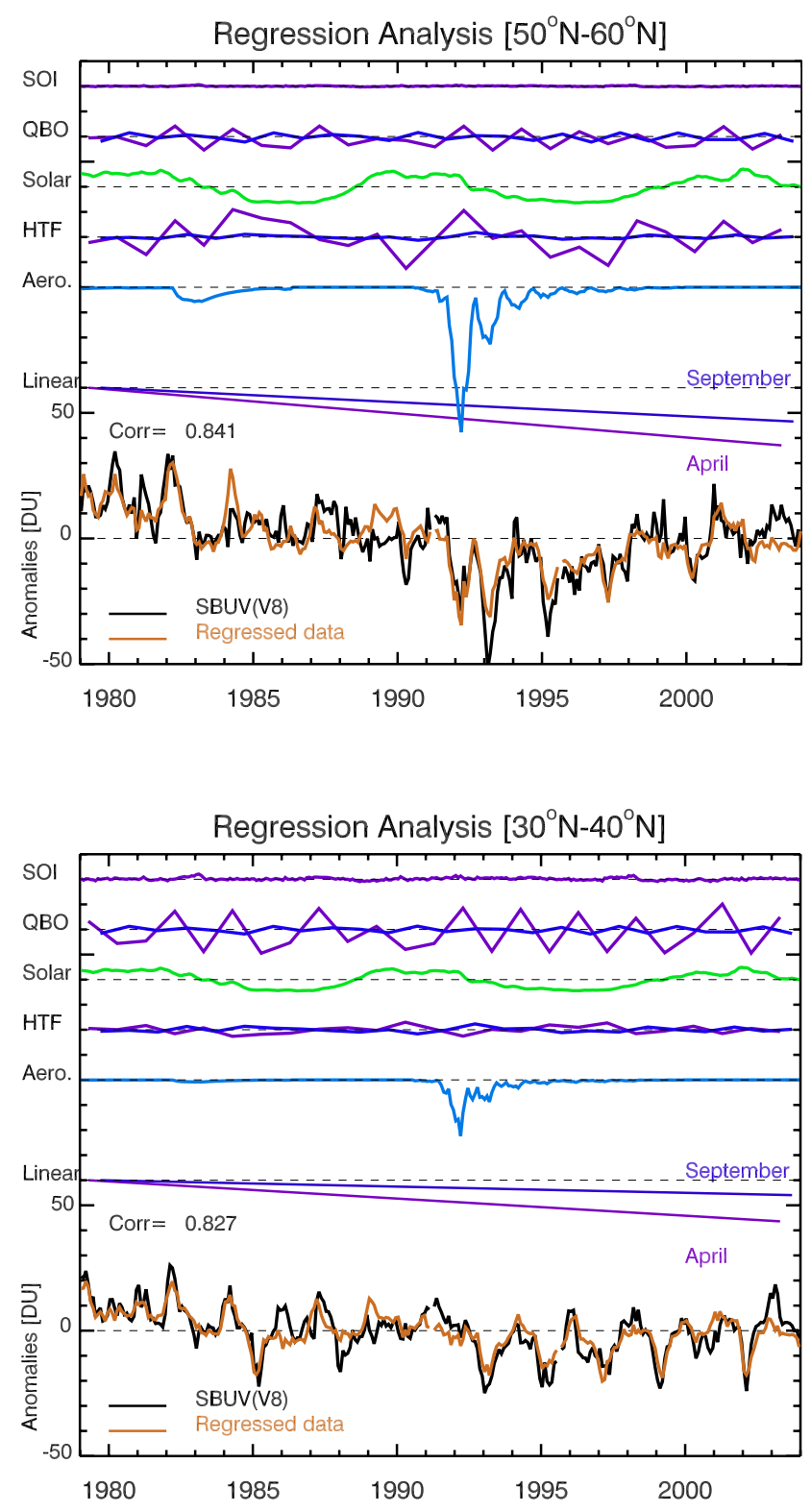

Fig. 5. Regression plots for the monthly mean total ozone anomaly from SBUV V8 data set for the $30^{\circ} \mathrm{N}-40^{\circ} \mathrm{N}$ (bottom) and $50^{\circ} \mathrm{N}-$ $60^{\circ} \mathrm{N}$ (top) latitude bands. In the bottom of each plot the fit (orange) along with the observational data (black) are shown. The ozone anomalies for both observations and model were calculated by subtracting the respective long-term mean for each month of the year from the monthly total ozone time series. In the top of each plot the contributions from individual explanatory variables are shown. Contributions from linear trend term, eddy heat flux, and QBO are only shown for April (violet) and September (blue), while others are shown for all months.

of the SBUV instruments. There appear to be no jumps in residuals after changes of instrument platforms confirming the consistency of the data set as stated earlier. For all latitude bands residuals do not show any significant auto-correlation after one Cochrane-Orcutt transformation. 

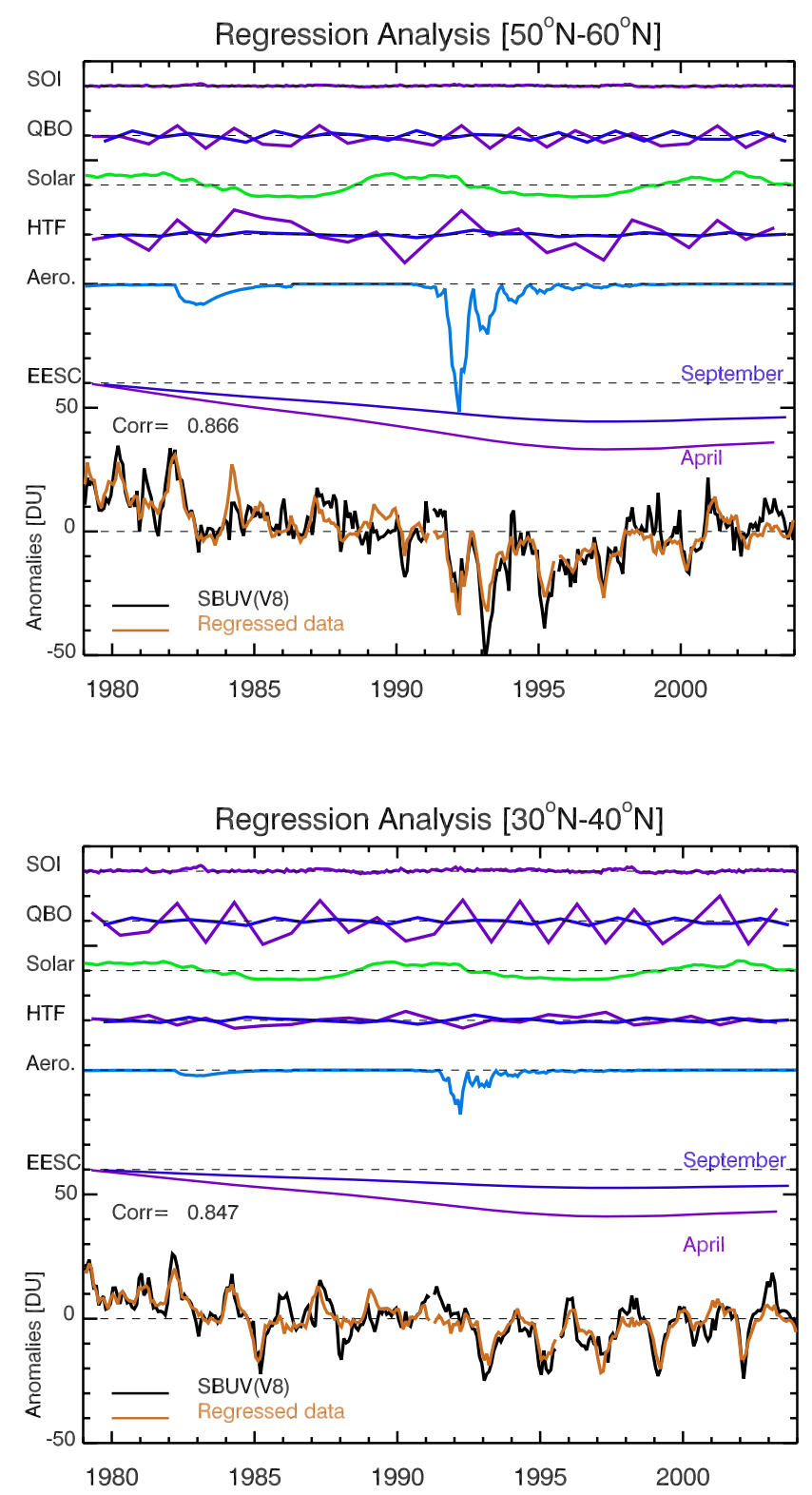

Fig. 6. Same as Fig. 5, but model fits with EESC terms replacing linear trend terms as indicated by Eq. (4).

Analyses have been performed for seven $10^{\circ}$ wide latitude bands from equator to $70^{\circ} \mathrm{N}$. Figure 8 shows the observed and modeled ozone anomalies for spring (April) and late summer (September) months for all latitude bands from $10^{\circ} \mathrm{N}-20^{\circ} \mathrm{N}$ to $60^{\circ} \mathrm{N}-70^{\circ} \mathrm{N}$ in the $\mathrm{NH}$. Ozone reconstructions displayed here are based upon regression with linear trend terms. Also shown are GOME observations that particularly after 2002 show somewhat lower values than SBUV. In general the linear decrease up to the mid-nineties and increase in the total ozone since then are clearly captured by the model for both months. As discussed earlier the September changes are closely coupled to changes in the previous
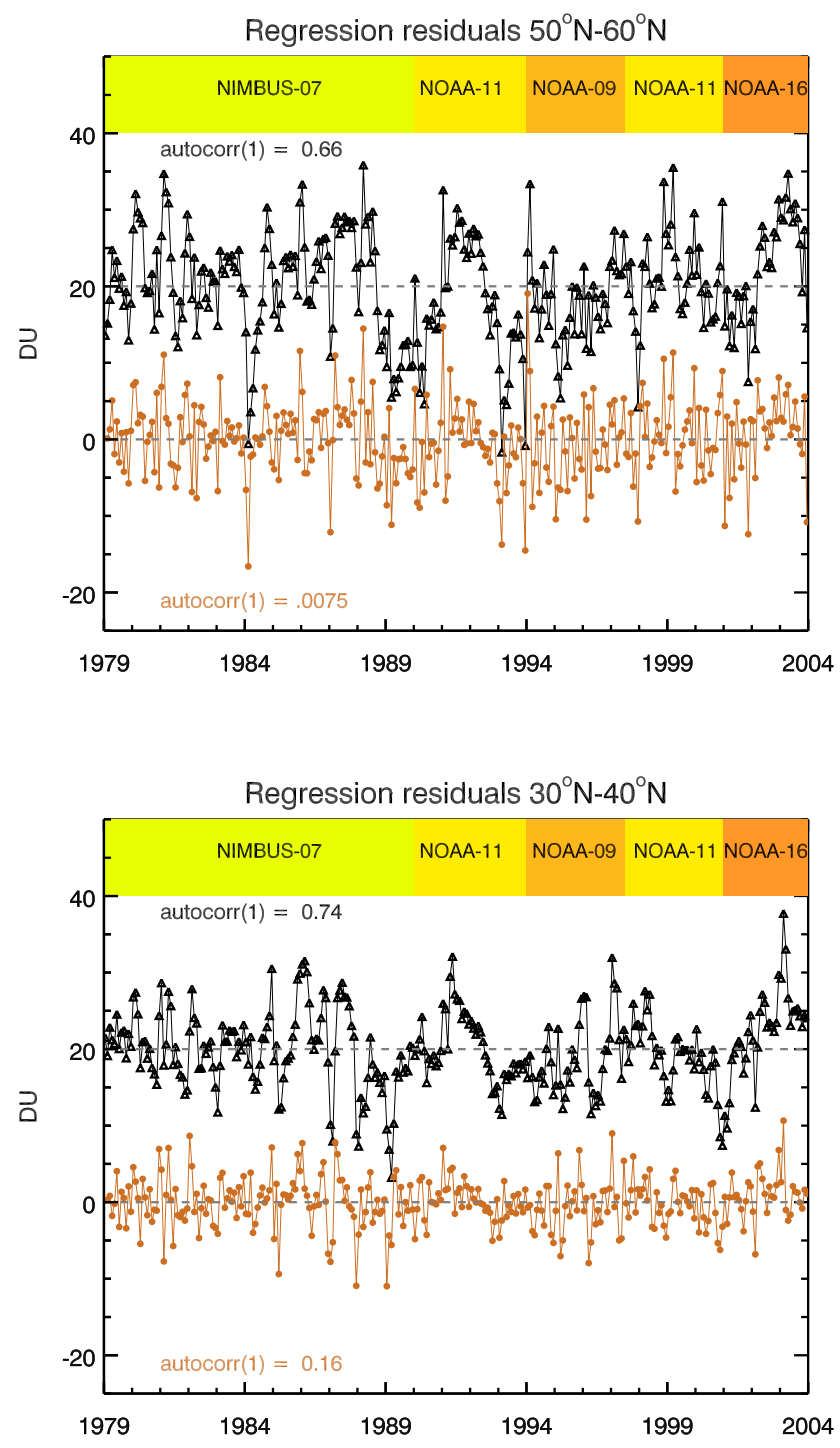

Fig. 7. Regression residuals in the $30^{\circ} \mathrm{N}-40^{\circ} \mathrm{N}$ (bottom) and $50^{\circ} \mathrm{N}-60^{\circ} \mathrm{N}$ (top) latitude bands. Black line marks the residuals from a regression without auto-regression correction (shifted by $+20 \mathrm{DU}$ for better clarity). The orange line marks the residual of the transformed model, e.g. residuals of the time series $T O Z(n)-\hat{\rho} \cdot T O Z(n-1)$, where $\hat{\rho}$ is the auto-correlation coefficient with time lag of one month before the transformation. Also indicated are the various satellite platforms for the SBUV instruments from which the SBUV ozone time series was constructed.

winter (Fioletov and Shepherd, 2003, 2005). It can be also noted that the modeled ozone anomaly agrees better with observations in the nineties and later than the earlier period. A likely explanation is the fact that both observational data as well as meteorological analyses from which most of the proxies have been derived have improved in quality in recent years (Uppala et al., 2006). 

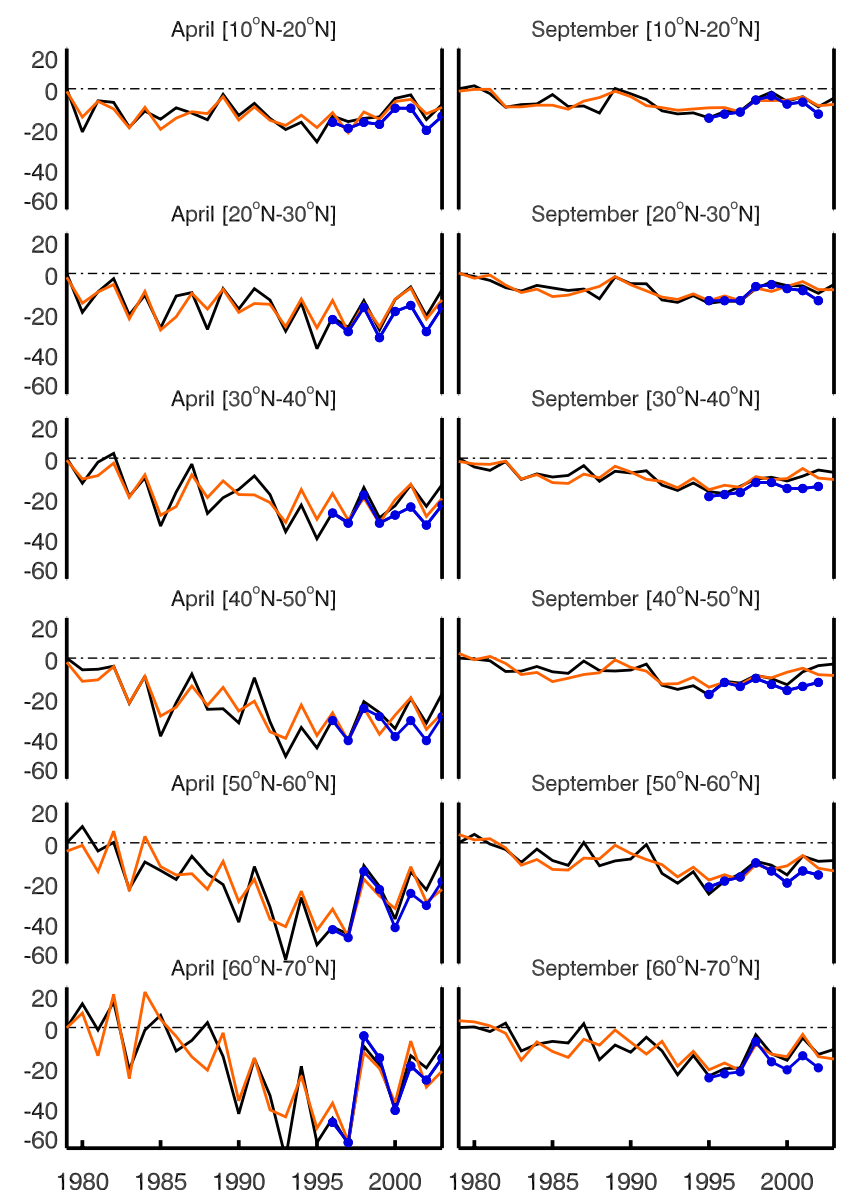

Fig. 8. Observed SBUV V8 (black) and modelled (orange) total ozone anomalies for all NH latitude bands in April (left) and September (right) based upon multi-variate regression (Eq. 3) with linear trend and eddy heat flux terms. Similar results are achieved when linear terms are replaced by EESC terms (Eq. 4). Also shown are observations from GOME in blue (1995-2003).

The ozone variability due to the different proxy terms in Eq. (3) is shown in Fig. 9 for all NH latitudes in April and September, respectively. The $2 \sigma$ variability has been calculated from the variance of the proxy time series multiplied by the corresponding fitting coefficient (Steinbrecht et al., 2003). The vertical bars for each explanatory variable account for the uncertainty in the fitting coefficients (alphas in Eq. 3). The $2 \sigma$ variabilities of the SBUV and modeled ozone time series are also shown (black and orange bars without vertical bars). In late spring, where usually the highest inter-annual variability is observed (up to $\pm 40 \mathrm{DU}$ ), the model tends to underestimate the observed variability by about $5 \mathrm{DU}$ at high latitudes during spring as shown in Fig. 9. This difference corresponds to a maximum of 15 DU unexplained $2 \sigma$ variance (as verified by the $2 \sigma$ value of the observed residual time series). In late summer the overall variability is reduced and the contribution from various processes are generally not statistically significant.
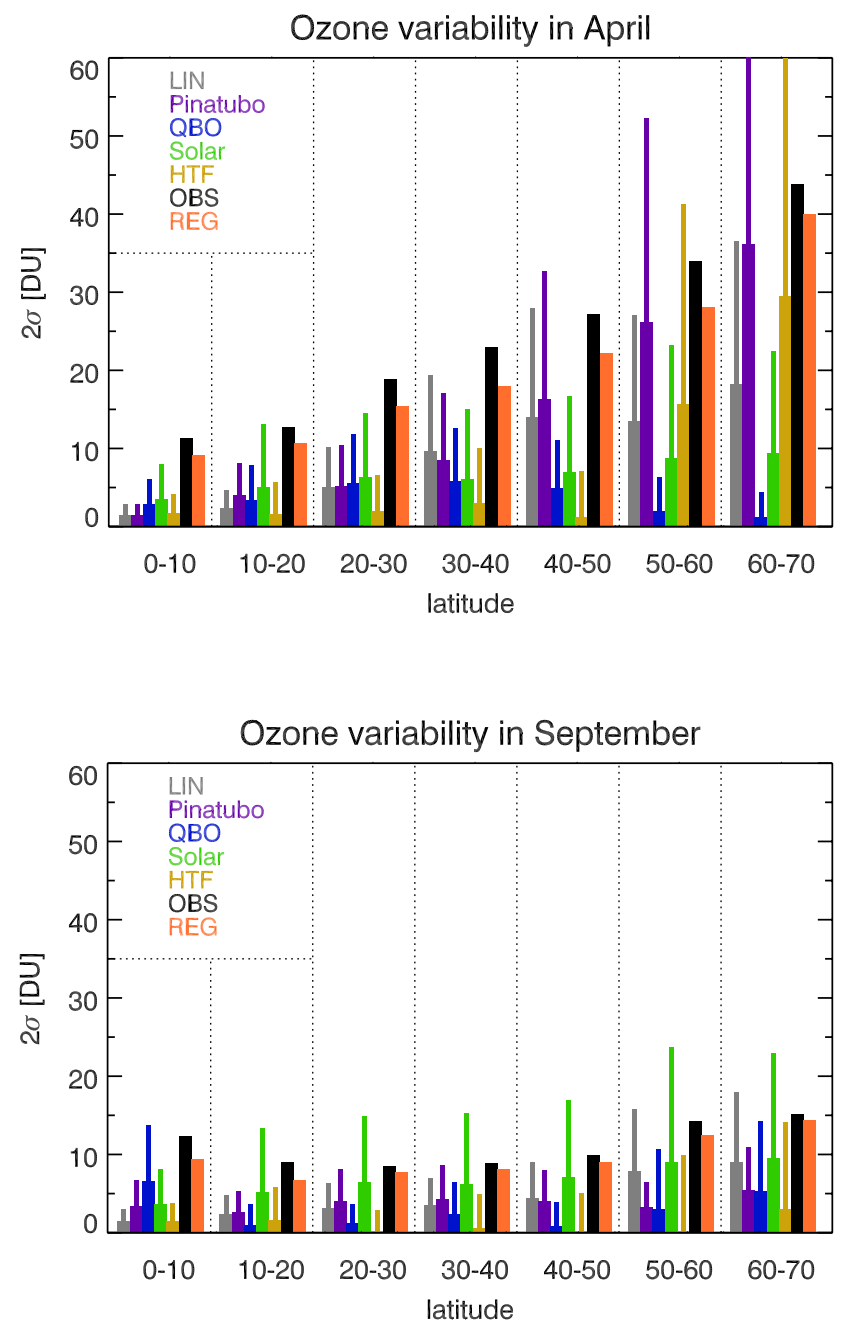

Fig. 9. Two- $\sigma$ ozone variability of individual processes in April (top) and September (bottom) from Eq. (3). Vertical bars indicate error contribution from the uncertainty of fitting coefficients in the regression equation. Black and orange bars are observations and model results, respectively.

Highest contribution to ozone variability at low latitudes are from QBO and solar variability (up to $\pm 5 \mathrm{DU}$ each). QBO influences are observed at all latitudes during spring while it is limited to lowest latitudes below $10^{\circ} \mathrm{N}$ during summmer/fall in agreement with Baldwin et al. (2001) and Steinbrecht et al. (2003). The solar cycle signature is observed at all latitudes and seasons. Separating solar term fitting into individual months (12 fitting constants) slightly reduces the solar signal variability in summer/fall by about 2 DU (not shown here). Various earlier studies (Solomon et al., 1996; Hood et al., 1997; Randel et al., 2002) suggested that it is difficult to separate the effect of solar cycle and volcanic eruption on the long-term ozone change. Both major volcanic eruptions, El Chichón in 1982 and Pinatubo in 1991, occurred during solar maximum conditions, in an 


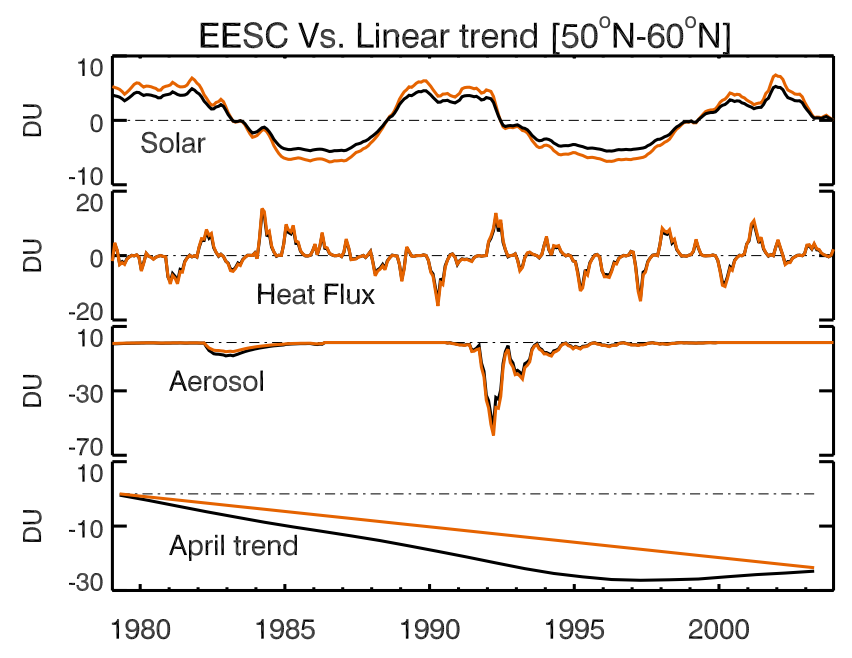

Fig. 10. Contribution from selected explanatory variables when either linear terms (orange) or EESC terms (black) are used in the full regression model of Eq. (3). Overall statistical significance $\left(R^{2}\right.$ value) does not change significantly, but contribution from aerosol term and solar flux term slightly differ.

easterly phase of QBO, and during a strong El-Niño event. Our analysis shows that the solar maximum of the present solar cycle has experienced no major volcanic eruption. That may improve the separability of stratospheric aerosol and solar influences. The rise of solar cycle 23 until early 2000s has positively contributed to the recent increase in total ozone in the absence of another major volcanic eruption. Nevertheless a few more years of data particularly during declining phase of the current solar cycle will be important to further strengthen our point made here (Steinbrecht et al., 2004).

Eddy heat flux contribution is observed to be maximum during winter months (up to $\pm 30 \mathrm{DU}$ ) at higher latitudes. This contribution is only significant beyond $50^{\circ} \mathrm{N}$ from January until May, but has non-negligible contribution at low latitudes (see Fig. 9). Apart from the eddy heat flux the largest variability is produced by the Pinatubo signal that reduced total ozone at high latitudes by about 60-70 DU during winter/spring 1991/92. In agreement with earlier trend assessments the volcanic aerosol contribution to stratospheric ozone is maximum during winter/spring and minimum during summer/fall (Bodeker et al., 2001, for instance). The effect from the El Chichón eruption is only very modest and decreases did not exceed 10 DU for all latitudes after 1983.

As shown in Figs. 5 and 6, ozone reconstructions using either linear trend or EESC terms (stratospheric chlorine loading trends) work about equally well. However, the choice of either terms may alter the impact from other processes. In Fig. 10 the contributions from solar, eddy heat flux, and Pinatubo aerosols are shown for both ozone reconstructions in the $50^{\circ} \mathrm{N}-60^{\circ} \mathrm{N}$ latitude band. Using linear trend terms, the solar and Pinatubo influence on ozone increases by about $4 \mathrm{DU}$ (from solar minimum to maximum) and 10 DU (addi-

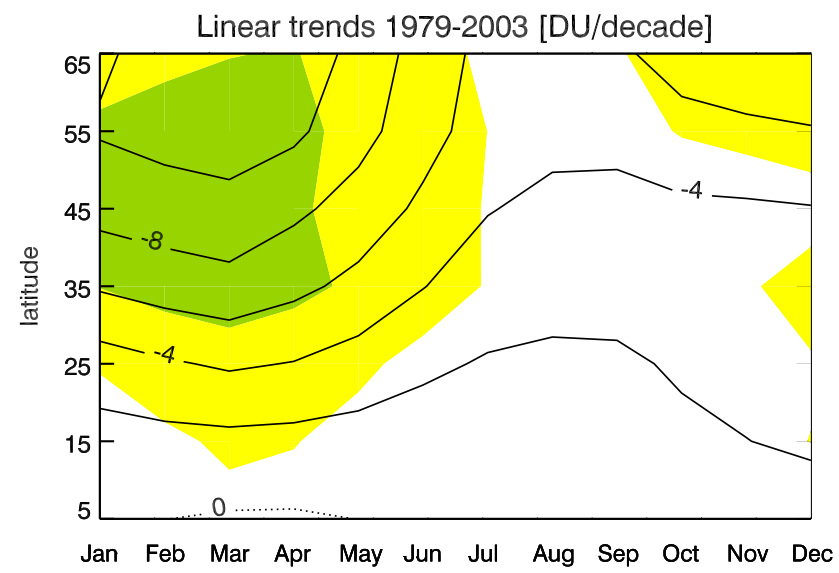

Fig. 11. Linear trends in DU/year for individual months using SBUV V8 total ozone for various NH latitude bands during the period 1979-2003 based upon the full regression model as described by Eq. (3). Linear trends significant at $2 \sigma$ level are observed at higher latitudes during winter/spring months (green shadings). Yellow shadings correspond to significance exceeding $1 \sigma$.

tional decline in April 1993), respectively. Modification of the eddy heat flux term is rather minor with respect to the choice of linear or EESC terms. A significant change is, however, observed in the linear part of the EESC trend until December 1995 that amounts to about -16 DU/decade in April (see Fig. 10). This is larger than the overall trend of the linear proxy of $-8 \mathrm{DU} /$ decade for the entire period until 2003.

Figure 11 shows the long-term ozone decrease from the linear trend assumed for the entire period up to 2003 for all latitudes and months based upon the full regression model as described by Eq. (3). The trends are statistically significant at the $2 \sigma$ level only in winter and early spring above $35^{\circ} \mathrm{N}$ with a maximum of $-10 \mathrm{DU} /$ decade in February at mid-latitudes. By replacing the linear trend terms in Eq. (3) with the EESC terms in the full regression model (see Eq. 4) leads to larger downward trends during the growth phase of the stratospheric chlorine loading until 1995 with maximum values of -15 to -18 DU/decade in February and March at high latitudes as shown in Fig. 12. This translates into a -17 to $-20 \mathrm{DU} / \mathrm{ppb}$ EESC change. The slope of the EESC curve in the declining phase after 1999 corresponds to about one third of the initial increasing rate (see Fig. 2), so that a recovery of up to 5 to $6 \mathrm{DU} /$ decade at high latitudes in winter/spring can be associated with the turnaround of the chlorine loading.

In a second step, the eddy heat flux terms were replaced by the PSC volume proxy (Eqs. 3, 4, and 5) and this has a significant effect on the EESC contribution by reducing the linear trend up to 1995 by nearly half at higher latitudes during winter/spring with a maximum declining trend of $10 \mathrm{DU} / \mathrm{decade}$. It practically removes the statistical significance of the EESC 


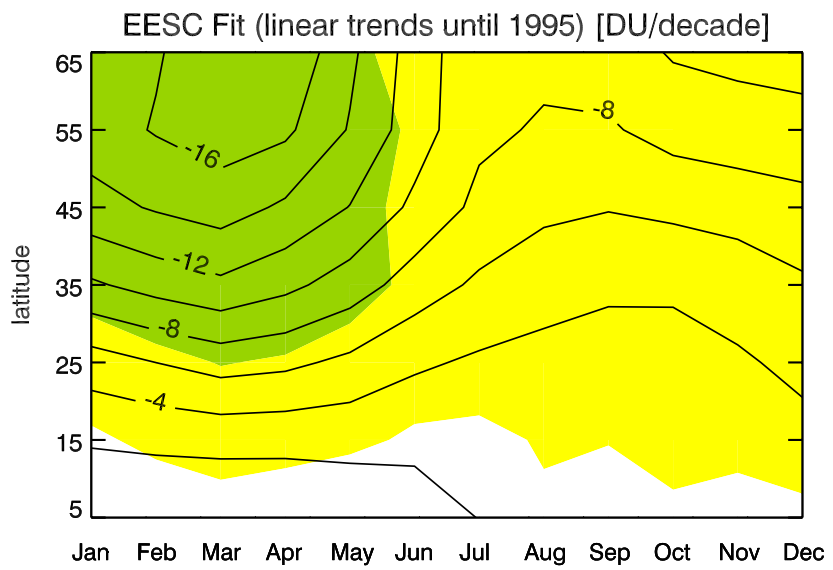

Fig. 12. Linear trends until end of 1995 in DU/year for individual months using SBUV V8 total ozone for various NH latitude bands from a fit using the same regression model as in Fig. 11, but EESC terms replacing the linear trend terms (see Eq. 4). Linear trends up to end of 1995 significant at $2 \sigma$ level are indicated by green shadings. Yellow shadings correspond to significance exceeding $1 \sigma$. A decrease of 12 DU/decade until 1995 is equivalent to a 4 DU/decade increase after the turnaround in EESC.

contribution (at $2 \sigma$ level) as shown in Fig. 13. Similar to Fig. 10, the effect on other terms from the exchange of PSC volume and eddy heat flux is shown in Fig. 14. In general only small changes in solar and aerosol components in the $50^{\circ} \mathrm{N}-60^{\circ} \mathrm{N}$ band are found when PSC volume replaces eddy heat flux terms. In Arctic winter 1999/2000 a drop of about $30 \mathrm{DU}$ can be associated to the polar ozone loss that exceeds the effect from eddy heat flux by a factor of about two. The PSC volume contribution is only significant during winter/spring at latitudes higher than about $50^{\circ} \mathrm{N}$ similar to the eddy heat flux. The mid-latitudes are influenced by polar ozone loss most likely via airmass mixing after the polar vortex break-up in early spring as discussed before (Knudsen and Grooss, 2000; Fioletov and Shepherd, 2005). Comparing the eddy heat flux and PSC volume contribution in Fig. 14, it is evident that during the nineties minima in eddy heat flux match minima in accumulated PSC volume, however, in the mid-eighties this is not the case for a couple of winters.

The contribution of the EESC turnaround to the recent $\mathrm{NH}$ ozone increase is fairly minor (up to 5-6 DU/decade in the regression with eddy heat flux or about $3 \mathrm{DU} /$ decade with PSC volume during the last five years) compared to other processes such as planetary wave driving (or PSC volume) as well as solar flux variability that explain roughly a $30 \mathrm{DU}$ increase in the $50^{\circ} \mathrm{N}-60^{\circ} \mathrm{N}$ band during winter months as shown in Fig. 10. When replacing eddy heat flux terms with PSC volume representing polar chemical ozone loss (Fig. 13), the EESC contribution standing for background gas phase chemistry has an insignificant impact (at the $2 \sigma$ level) on the total ozone trend. In other words, the variability in polar (here Arctic) ozone loss suffices to explain major

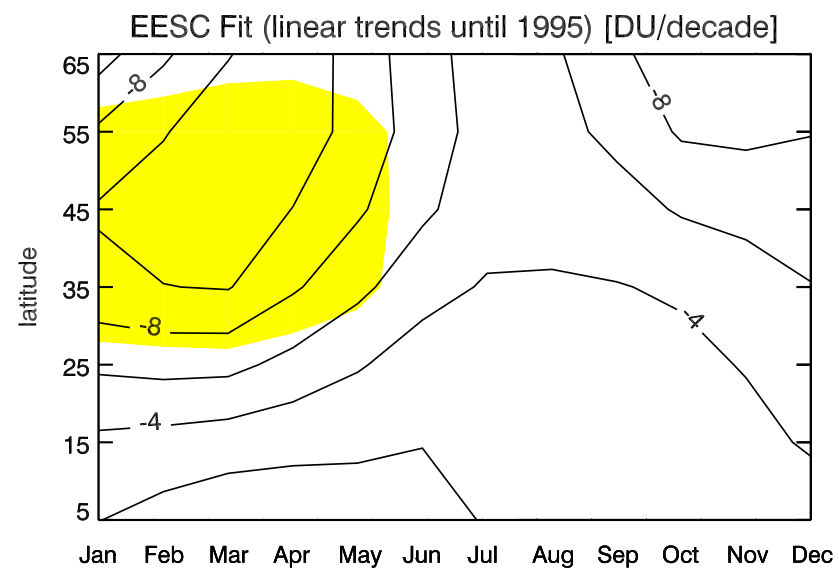

Fig. 13. The same as Fig. 12 except that in the full regression model eddy heat flux terms were now replaced by PSC volume proxies (Eq. 5). Yellow shadings corresponds to significance exceeding $1 \sigma$. Trends are statistically insignificant at $2 \sigma$. A decrease of $9 \mathrm{DU} /$ decade until 1995 is equivalent to a 3 DU/decade increase after the turnaround in EESC.

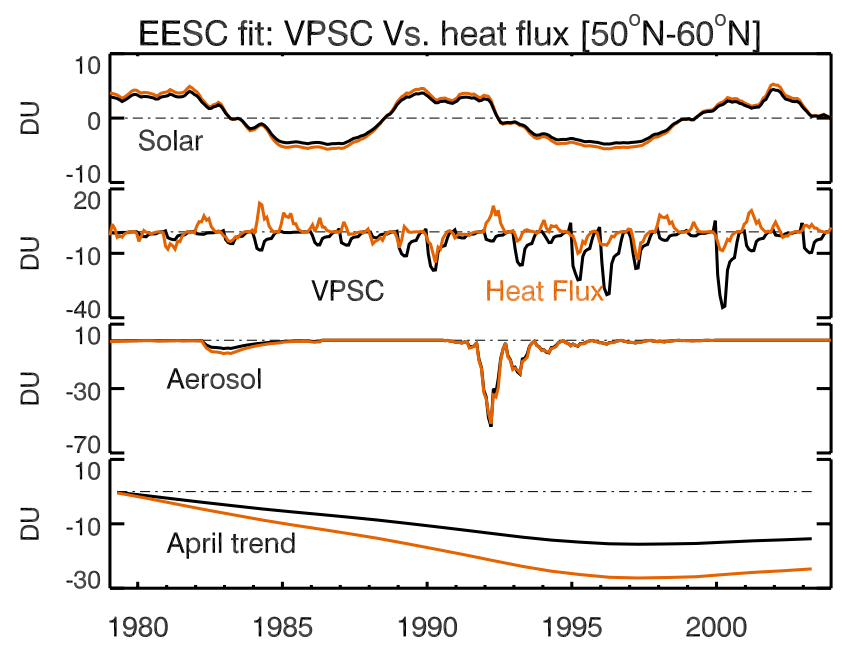

Fig. 14. Contribution from selected explanatory variables when either eddy heat flux (orange) or PSC volume proxy terms (black) are used in the full regression model (Eq. 3) with EESC contribution (Eq. 4) for the background gas phase chemistry. Little change is observed in the solar and Pinatubo aerosol component of total ozone, but EESC contribution is reduced at higher latitudes during winter and spring.

parts of the observed turnaround in NH midlatitude and polar ozone after decreases until early 1990s that experienced a series of cold Arctic stratospheric winters (Pawson and Naujokat, 1999). It is important to note that the polar ozone loss is dynamically driven by temperature changes related to the wave driving as discussed before. This also means that the polar ozone loss proxy accounts in addition for dynamically driven ozone variability related to ozone transport and synoptic meteorology (Hood and Soukharev, 2005; Wohltmann et al., 2005). 


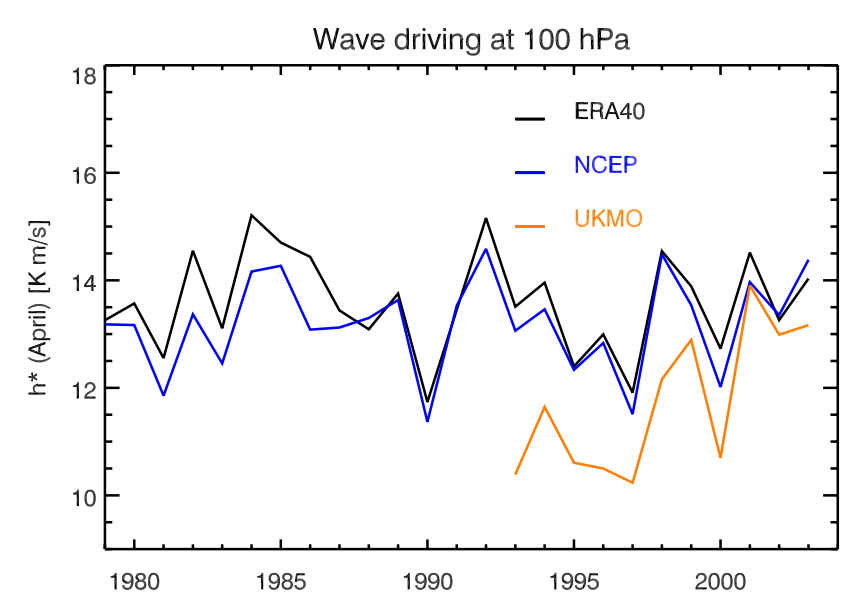

Fig. 15. Average winter eddy heat flux at $100 \mathrm{hPa}$ (from October to April) between $45^{\circ} \mathrm{N}$ and $75^{\circ} \mathrm{N}$ from various meteorological analysis: ERA-40 reanalysis (Simmons and Gibson, 2000), NCEP reanalysis (Kalnay et al., 1996), and UKMO (METO) data sets (Swinbank and O'Neill, 1994). Differences between analyses are due to different model resolution and different parameterization schemes. All analyses show an increase in winter eddy heat flux since midnineties.

The polar ozone loss proxy (cumulative PSC volume) is mainly associated with the nonlinear chemical effect that explains the rapid depletion during winter and spring, while the EESC (or linear trend) proxy stands for the (slower) background gas phase chemistry affecting long term changes in ozone. Both processes are not completely separable as suggested from our analysis, since both proxies contain the EESC function. But this separation is still valuable for approximating the various chemical causes of observed ozone variability.

In the linear trend model from Eq. (3), so-called change of trend terms (beginning in January 1996) have been included as proposed by Reinsel et al. (2005). In our study the change of trend terms were statistically insiginificant at $1 \sigma$ (not shown here), most likely due to the too short period after 1995.

The observed increase in eddy heat flux in recent winters strengthened ozone transport from lower to higher latitudes and increased Arctic stratospheric temperatures (Fusco and Salby, 1999; Newman et al., 2001; Weber et al., 2003). This is in line with observations of smaller PSC volumes in recent years (Manney et al., 2005) albeit reducing the polar ozone loss contribution. A positive trend in the eddy heat flux is observed in all recent reanalysis data sets as shown in Fig. 15. Even though there are significant differences in assimilation schemes for ERA-40, NCEP and UKMO, all three analyses confirm the recent increase. This indicates that there are changes in the strength of the Brewer-Dobson circulation and associated with it changes in polar and tropical lower stratospheric temperatures. Increases in lower stratospheric temperatures over the $\mathrm{NH}$ polar region and decrease

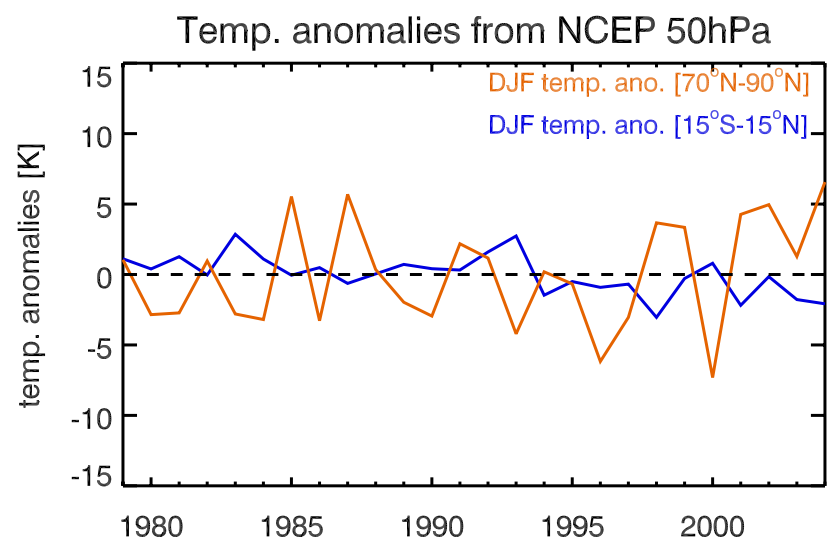

Fig. 16. December to February (DJF) temperature anomalies from NCEP reanalysis dataset over the Arctic $\left(70^{\circ} \mathrm{N}-90^{\circ} \mathrm{N}\right)$ and the tropics $\left(15^{\circ} \mathrm{S}-15^{\circ} \mathrm{N}\right)$ at $50 \mathrm{hPa}$. Decrease in lower stratospheric temperatures over tropics and increase in polar stratospheric temperature since 1997 (except for 2000) is clearly observed. Same features are observed in ERA-40 and UKMO(METO) datasets. MSU channel 4 dataset, which samples the atmosphere between 16-20 km, shows a similar signature.

over tropical regions during winter months (DJF) are the expected responses from the circulation changes as shown in Fig. 16 (Yulaeva et al., 1994; Newman et al., 2001).

\section{Conclusions}

In this study total ozone data from SBUV and other satellite data is used to investigate the cause of recent increases in $\mathrm{NH}$ total ozone. Several new proxies such as the cumulative eddy heat flux, cumulative PSC volume, and EESC have been added in a multivariate linear regression model as explanatory variables standing for chemical and dynamical processes that are known to contribute to inter-annual ozone variability. The effects of various dynamical and chemical processes have been systematically included and analyzed. Important conclusions are:

1. One of the key findings is that recent increases in the $\mathrm{NH}$ total ozone are mainly related to increases in eddy heat flux (or reduced polar ozone loss after a series of cold Arctic winters in the mid-nineties (Pawson and Naujokat, 1999)) and, to a lesser extent, increased solar activity. The series of cold Arctic winters with extended PSC volumes at the peak of the stratospheric chlorine loading in combination with the strong Pinatubo volcanic event contributed to the pronounced minimum in total ozone anomalies during the mid-nineties at middle to high northern latitudes. This made the recent increase in total ozone appear to be rather rapid. At high northern latitudes (above $50^{\circ} \mathrm{N}$ ) the contribution to the recent increase is about $+10 \mathrm{DU}$ from solar cycle (all seasons) and a maximum of $+50 \mathrm{DU}$ and $+20 \mathrm{DU}$ 
from stratospheric aerosols and planetary wave driving, respectively, during winter/spring. Replacing the eddy heat flux terms by the PSC volume proxies, the contribution is +30 DU due to reduced polar ozone loss. The linear downward trend for the entire period until end of 2003 has dropped to a maximum of -10 DU/decade during winter/spring that is about half of the downward trend of $-16 \mathrm{DU} /$ decade until end of 1995 as derived from fitting EESC terms in the regression model.

2. Most of earlier studies have pointed out the difficulties in finding out the exact influence of stratospheric aerosol loading and solar variability on ozone. The recent solar cycle 23 experienced no major volcanic eruption and, therefore, solar term and aerosol loading signatures are better separable in the regression.

3. When the linear trend term is replaced by the EESC term, overall statistical significance of the regression model does not change. Both the linear trend and the EESC terms are commonly associated with gas phase chemistry involving halogens. The relative contribution of the eddy heat flux (or polar ozone loss) and the solar term are slightly reduced and a modest decrease in aerosol contribution is found with the EESC model. The turnaround in the EESC after peaking in 1997 only contributed in a minor way to the recent increases in $\mathrm{NH}$ total ozone with a maximum of 5-6 DU/decade during winter/spring at high latitudes.

4. The recent increase in middle to high latitude $\mathrm{NH}$ ozone since the mid-nineties led in a recent study to the conclusion that this may be a result of the recent decline in EESC (Reinsel et al., 2005). They analyzed total ozone data from SBUV data as used here and identified a positive and significant change in NH trends after 1996 with and without contribution from dynamical variables included in their statistical model. We find that dynamical factors and, associated with them, variations in chemical processes such as polar ozone loss are believed to have contributed to the recent ozone increase in $\mathrm{NH}$ in combination with rising solar activity during solar cycle 23. Similar conclusions have been reported from a model study that identified dynamical processes as the main cause for the recent ozone increase in the NH (Hadjinicolaou et al., 2005).

5. Changes in the strength of the residual circulation are observed in recent years. Using ERA-40, NCEP, and UKMO reanalysis data sets, it has been found that there has been an increase in the eddy heat flux at $100 \mathrm{hPa}$ in recent years (Fig. 15). This is reflected in the lower stratospheric temperature over the $\mathrm{NH}$ polar cap region which has been increasing in recent years and is accompanied by a cooling of the tropical lower stratosphere (except for year 2000) as shown in Fig. 16. It is consistent with our understanding of temperature response to wave driving (Yulaeva et al., 1994; Newman et al., 2001). Most climate model results indicated that in a future changing climate global warming will lead to stratospheric cooling that will have a negative impact on the expected ozone recovery (Shindell et al., 1999b). However, some climate model runs indicate that $\mathrm{NH}$ planetary wave driving may increase as a result of climate change (Butchart and Scaife, 2001; Schnadt et al., 2002). It remains to be seen if the recent increase in planetary wave driving (and less polar ozone loss) that was responsible for the recent $\mathrm{NH}$ total ozone increase is just part of a natural decadal variability or will persist. If the latter is the case, we may then expect an accelerated ozone recovery due to possible climate change.

Acknowledgements. This project was supported in parts by BMBF grant 7ATF42 (GOMSTRAT) and 7ATC08 (DYCHO) within the AFO2000 national research programme and EU project EVK2-CT-2001-00133 (CANDIDOZ, and DFG project SOLOZON within the national CAWSES programme). We thank the NOAA and NASA teams for providing SBUV and TOMS data. The support of NCEP, UK Met Office, and ECMWF for providing the various meteorological analyses is gratefully acknowledged.

Edited by: M. Dameris

\section{References}

Anderson, J., Russell III, J. M., Solomon, S., and Deaver, L. E.: Halogen Occultation Experiment confirmation of stratospheric chlorine decreases in accordance with the Montreal Protocol, J. Geophys. Res., 105, 4483-4490, 2000.

Andrews, D. G., Holton, J. R., and Leovy, C. B.: Middle Atmosphere Dynamics, Academic Press, 1987.

Baldwin, M. P. and Dunkerton, T. J.: Propagation of the Arctic Oscillation from the stratosphere to the troposphere, J. Geophys. Res., 104, 30 937-30 946, 1999.

Baldwin, M. P., Gray, L. J., Dunkerton, T. J., Hamilton, K., , Haynes, P. H., Randel, W. J., Holton, J. R., Alexander, M. J., Hirota, I., Horinouchi, T., Jones, D. B. A., Kinnersley, J. S., Marquardt, C., Sato, K., and Takahashi, M.: The Quasi-Biennial Oscillation, Rev. Geophys., 39, 179-229, 2001.

Barthia, P. K., Wellemeyer, C. G., Taylor, S. L., Nath, N., and Gopolan, A.: Solar Backscatter (SBUV) Version 8 profile algorithm, in: Proceedings of the Quadrennial Ozone Symposium2004, edited by: Zerefos, C., p. 295-296, Athens, Greece, ISBN 960-630-103-6, 2004.

Bodeker, G. E., Boyd, I. S., and Matthews, W. A.: Trends and variability in vertical ozone and temperature profiles measured by ozone sondes at Lauder, New Zealand: 1986-1996, J. Geophys. Res., 103, 28 661-28 681, 1998.

Bodeker, G. E., Scott, J. C., Kreher, K., and McKenzie, R. L.: Global ozone trends in potential vorticity coordinates using TOMS and GOME intercompared against the Dobson network: 1978-1998, J. Geophys. Res., 106, 23 029-23 042, 2001.

Bowman, K. P.: Global patterns of the quasi-biennial oscillation in total ozone, J. Atmos. Sci., 46, 3328-3343, 1989. 
Brasseur, G.: The response of the middle atmosphere to long-term and short-term solar variability: A two-dimensional model, J. Geophys. Res., 98, 23 079-23 090, 1993.

Brühl, C., Crutzen, P. J., and Grooss, J.: High-latitude, summertime $\mathrm{NO}_{\mathrm{x}}$ activation and seasonal ozone decline in the lower stratosphere: Model calculations based upon HALOE on UARS, J. Geophys. Res., 103, 3587-3597, 1998.

Butchart, N. and Scaife, A. A.: Removal of chlorofluorocarbons by increased mass exchange between the stratosphere and troposphere in a changing climate, Nature, 410, 799-802, 2001.

Chandra, S. and Stolarski, R. S.: Recent trends in stratospheric total ozone: Implications of dynamical and El Chichón perturbations, Geophys. Res. Lett, 18, 2277-2280, 1991.

Chipperfield, M. P. and Jones, R. L.: Relative influences of atmospheric chemistry and transport on Arctic ozone trends, Nature, 400, 551-554, 1999.

Cochrane, D. and Orcutt, G. H.: Application of least squares regression to relationships containing autocorrelated error terms, J. Amer. Stat. Assoc., 44, 32-61, 1949.

Coldewey-Egbers, M., Weber, M., Lamsal, L. N., de Beek, R., Buchwitz, M., and Burrows, J. P.: Total ozone retrieval from GOME UV spectral data using the weighting function DOAS approach, Atmos. Chem. Phys., 5, 5015-5025, 2005.

Farman, J. C., Gardiner, B. G., and Shanklin, J. D.: Large losses of total ozone in Antarctica reveal seasonal $\mathrm{ClO}_{\mathrm{x}} / \mathrm{NO}_{\mathrm{x}}$ interaction, Nature, 315, 207-210, 1985.

Fioletov, V. E. and Shepherd, T. G.: Seasonal persistence of midlatitude total ozone anomalies, Geophys. Res. Lett., 30, doi:10.1029/2002GL016739, 2003.

Fioletov, V. E. and Shepherd, T. G.: Summertime total ozone variations over middle and polar latitudes, Geophys. Res. Lett, 32, L04807, doi:10.1029/2004GL022080, 2005.

Frith, S., Stolarski, R., and Barthia, P. K.: Implications of Version 8 TOMS and SBUV data for long-term trend, in: Proceedings of the Quadrennial Ozone Symposium-2004, edited by: Zerefos, C., p. 65-66, Athens, Greece, 2004.

Fusco, A. C. and Salby, M. L.: Interannual variations of total ozone and their relationship to variations of planetary wave activity, J. Climate, 12, 1619-1629, 1999.

Gettelman, A., Randel, W. J., Massie, S., Wu, F., Read, W. G., and Russell III, J. M.: El-Nino as a natural experiment for studying the tropical tropopause region, J. Climate, 14, 3375-3392, 2001.

Hadjinicolaou, P., Pyle, J. A., and Harris, N. R. P.: The recent turnaround in stratospheric S4810 ozone over northern middle latitudes: A dynamical modeling perspective, Geophys. Res. Lett., 32, L12821, doi:10.1029/2005GL022476, 2005.

Hanson, D. and Mauersberger, K.: Laboratory studies of nitric acid tryhydrate: Implications for the south polar stratosphere, Geophys. Res. Lett., 15, 855-858, 1988.

Hofmann, D. J. and Solomon, S.: Ozone destruction through heterogeneous chemistry following the eruption of El Chichon, J. Geophys. Res., 94, 5029-5041, 1989.

Holton, J. and Tan, H.-C.: The influence of the equatorial quasibiennial oscillation on the global circulation at $50 \mathrm{mb}$, J. Atmos. Sci., 37, 2200-2208, 1980.

Hood, L. L. and Soukharev, B. E.: Interannual variations of total ozone at northern midlatitudes correlated with EP flux and potential vorticity, J. Atmos. Sci., 62, 3724-3740, 2005.

Hood, L. L., McCormick, J. P., and Labitzke, K.: An investigation of dynamical contributions to midlatitude ozone trends in winter, J. Geophys. Res, 102, 13 079-13 093, 1997.

Jackman, C., Fleming, E., and Vitt, F.: Influence of extremely large solar proton events in a changing stratosphere, J. Geophys. Res., 105, 11 659-11670, 2000.

Jackman, C. H., Fleming, E. L., Chandra, S., Considine, D. B., and Rosenfield, J. E.: Past, present, and future modeled ozone trends with comparisons to observed trends, J. Geophys. Res., 101, 28 753-28 768, 1996.

Kalnay, E., Kanamitsu, M., Kistler, R., Collins, W., Deaven, D., Gandin, L., Iredell, M., Saha, S., White, G., Woolen, J., Zhu, Y., Chelliah, M., Ebisuzaki, W., Higgins, W., Janowiak, J., Mo, K. C., Ropelewski, C., Wang, J., Leetma, A., Reynolds, R., Jenne, R., and Joseph, D.: The NCEP/NCAR 40-year reanalysis project, Bull. Amer. Meteorol. Soc., 77, 437-471, 1996.

Kleinböhl, A., Bremer, H., von König, M., Küllmann, H., Künzi, K., Goede, A. P. H., Browell, E. V., Grant, W. B., Toon, G. C., Blumenstock, T., Galle, B., Sinnhuber, B., and Davies, S.: Vortexwide denitrification of the Arctic polar stratosphere in winter 1999/2000 determined by remote observations, J. Geophys. Res., 108, 8305, doi:10.1029/2001JD001042, 2003.

Knudsen, B. M. and Grooss, J.: Northern midlatitude stratospheric ozone dilution in spring modeled with simulated mixing, J. Geophys. Res., 105, 6885-6890, 2000.

Kodera, K. and Kuroda, Y.: Dynamical response to the solar cycle: Winter stratopause and lower stratosphere, J. Geophys. Res., 107, 4749, doi:310.1029/2002JD002224, 2002.

Labitzke, K. and van Loon, H.: Some recent studies of probable connections between solar and atmospheric variability, Ann. Geophys., 11, 1084-1094, 1993.

Labow, G. J., McPeters, R. D., and Barthia, P. K.: A comparison of TOMS \& SBUV Version 8 total column ozone data with data from ground, in: Proceedings of the Quadrennial Ozone Symposium-2004, edited by: Zerefos, C., p. 123-124, Athens, Greece, ISBN 960-630-103-6, 2004.

Lait, L. R., Schoeberl, M., and Newman, P.: Quasi-Biennial modulation of the Antarctic ozone depletion, J. Geophys. Res., 94, 11 559-11 571, 1989.

Logan, J. A., Jones, D. B. A., Megretskaia, I. A., Oltmans, S. J., Johnson, B. J., Voemel, H., Randel, W. J., Kimani, W., and Schmidlin, F. J.: Quasibiennial oscillation in tropical ozone as revealed by ozonesonde and satellite data, J. Geophys. Res., 108, doi:4244, doi:10.1029/2002JD002170, 2003.

Manney, G. L., Krueger, K., Sabutis, J. L., Sena, S. A., and Pawson, S.: The remarkable 2003/2004 winter and other recent warm winters in the Arctic stratosphere since the late 1990s, J. Geophys. Res., 110, D04107, doi:10.1029/2004JD005367, 2005.

McCormack, J. P., Hood, L. L., Nagatani, R., Miller, A. J., Planet, W. G., and McPeters, R. D.: Approximate separation of volcanic and 11-year signals in the SBUV-SBUV/2 total ozone record over the 1979-1995 period, Geophys. Res. Lett., 24, 2729-2732, 1997.

McLinden, C. A., Olsen, S. C., Hannegan, B., Wild, O., Prather, M. J., and Sundet, J.: Stratospheric ozone in 3-D models: a simple chemistry and the cross-tropopause flux, J. Geophys. Res., 105, 14 653-14 665, 2000.

Miller, A. J., Hollandsworth, S. M., Flynn, L. E., Tiao, G. C., Reinsel, G. C., Bishop, L., McPeters, R. D., Planet, W. G., DeLuisi, J. J., Mateer, C. L., Wuebbles, D., Kerr, J., and Nagatani, R. M.: 
Comparisons of observed ozone trends and solar effects in the stratosphere through examination of ground-based Umkehr and combined solar backscattered ultraviolet (SBUV) and SBUV 2 satellite data, J. Geophys. Res., 101, 9017-9021, 1996.

Molina, M. J. and Rowland, F. S.: Stratospheric sink for chlorofluoromethanes: chlorine atom catalysed destruction of ozone, Nature, 249, 810-812, 1974.

Newman, P. A., Nash, E. R., and Rosenfield, J. E.: What controls the temperature of the Arctic stratosphere during the spring?, J. Geophys. Res., 106, 19 999-20 010, 2001.

Parrish, A., Connor, B. J., Tsou, J. J., Beyerle, G., McDermid, I. S., and Hollandsworth, S. M.: Microwave ozone and lidar aerosol profile observations at Table Mountain, California, following the Pinatubo eruption, J. Geophys. Res., 208, 20 201-22 208, 1998.

Pawson, S. and Naujokat, B.: The cold winters of the middle 1990s in the northern lower stratosphere, J. Geophys. Res., 104, 14 209-14 222, 1999.

Plets, H. and Vynckier, C.: A comparative study of statistical total column ozone forecasting model, J. Geophys. Res., 105, 26503 26517, 2000.

Plumb, R. A. and Semeniuk, A.: Downward migration of extratropical zonal wind anomalies, J. Geophys. Res., 108, 4223, doi:10.1029/2002JD002773, 2003.

Randel, W. J. and Cobb, J. B.: Coherent variations of monthly mean column ozone and lower stratospheric temperature, J. Geophys. Res., 99, 5433-5447, 1994.

Randel, W. J., Wu, F., Russell III, J. M., Waters, J. W., and Froidevaux, L.: Ozone and temperature changes in the stratosphere following the eruption of Mt. Pinatubo, J. Geophys. Res., 100, 16 753-16 764, 1995.

Randel, W. J., Stolarski, R. S., Cunnold, D. M., Logan, J. A., Newchurch, M. J., and Zawodny, J. M.: Trends in the vertical distribution of ozone, Science, 285, 1689-1692, 1999.

Randel, W. J., Wu, F., and Stolarski, R. S.: Changes in column ozone correlated with the stratospheric EP flux, J. Meteorol. Soc. Japan, 80, 849-862, 2002.

Reed, R. J.: A tentative model of the 26-month oscillation in tropical latitudes, Q. J. Meteorol. Soc., 90, 441-466, 1964.

Reinsel, G. C., Weatherhead, E. C., Tiao, G. C., Miller, A. J., Nagatani, R. M., Wuebbles, D. J., and Flynn, L. E.: On detection of turnaround and recovery in trend for ozone, J. Geophys. Res., 107, 4078, doi:10.1029/2001JD000500, 2002.

Reinsel, G. C., Miller, A. J., Weatherhead, E. C., Flynn, L. E., Nagatani, R. M., Tiao, G. C., and Wuebbles, D. J.: Trend analysis of total ozone data for turnaround and dynamical contributions, J. Geophys. Res., 110, D16306, doi:10.1029/2004JD004662, 2005.

Rex, M., Salawitch, R. J., von der Gathen, P., Harris, N. R. P., Chipperfield, M. P., and Naujokat, B.: Arctic ozone loss and climate change, Geophys. Res. Lett., 31, L04116, doi:10.1029/2003GL018844, 2004.

Rind, D.: The sun's role in climate variations, Science, 296, 673677, 2002.

Salby, M. L. and Callaghan, P. E.: Interannual changes of the stratospheric circulation: relationship to ozone and tropospheric structure, J. Climate, 15, 3673-3685, 2002.

Sato, M., Hansen, J. E., McCormack, M. P., and Pollack, J. B.: Stratospheric aerosol optical depth, J. Geophys. Res., 98, 18501990, 1993

Schnadt, C., Dameris, M., Ponater, M., Hein, R., Grewe, V., and
Steil, B.: Interaction of atmospheric chemistry and climate and its impact on stratospheric ozone, Clim. Dyn., 18, 501-518, 2002.

Shindell, D., Rind, D., Balachandran, N., Lean, J., and Lonergan, P.: Solar cycle variability, ozone, and climate, Science, 284, 305308, 1999a.

Shindell, D. T., Miller, R. L., Schmidt, G. A., and Pandolfo, L.: Simulation of recent northern winter climate trends by greenhouse-gas forcing, Nature, 399, 452-455, $1999 \mathrm{~b}$.

Shiotani, M.: Annual Quasi-Biennial, and El Nino-Southern Oscillation (ENSO) time-scale variations in equatorial ozone, J. Geophys. Res., 97, 7625-7633, 1992.

Simmons, A. J. and Gibson, J. K.: The ERA-40 Project Plan, Tech. rep., ECMWF, Reading UK, ERA-40 project report series no. 1, 2000.

Sinnhuber, M., Burrows, J., Chipperfield, M. P., Jackman, C. H., Kallenrode, M.-B., Künzi, K. F., and Quack, M.: A model study of the impact of magnetic field structure on atmospheric composition during solar proton events, Geophys. Res. Lett., 30, 1818 , doi:10.1029/2003GL017625, 2003.

Solomon, S.: Stratospheric ozone depletion: A review of concepts and history, Rev. Geophys., 101, 275-316, 1999.

Solomon, S., Portman, R. W., Garcia, R. R., Thomason, L. W., Poole, L. R., and McCormack, M. P.: The role of aerosol variations in anthropogenic ozone depletion at northern midlatitudes, J. Geophys. Res., 101, 6713-6727, 1996.

SPARC: Assessment of trends in the vertical distribution of ozone, in WMO Ozone Research and Monitoring Project Report No. 34, p. 3413-3418, World Climate Research Programme, WCRP113,WMO/TD-No. 1043, 1998.

Staehelin, J., Harris, N., Appenzeller, C., and Eberhard, J.: Ozone trends: A Review, Rev. Geophys., 39, 231-290, 2001.

Steinbrecht, W., Hassler, B., Claude, H., Winkler, P., and Stolarski, R. S.: Global distribution of total ozone and lower stratospheric temperature variations, Atmos. Chem. Phys., 3, 34113449, 2003.

Steinbrecht, W., Claude, H., and Winkler, P.: Enhanced upper stratospheric ozone: Sign of recovery or solar cycle effect?, J. Geophys. Res., 109, 6713-6727, 2004.

Stolarski, R. S. and Cicerone, R. J.: Stratospheric chlorine: a possible sink for ozone, Can. J. Chem., 52, 1610-1615, 1974.

Swinbank, R. and O'Neill, A.: A stratosphere-troposphere data assimilation system, Mon. Wea. Rev., 122, 686-702, 1994.

Tiao, G., Reinsel, G., Xu, D., Frederick, J. H., Zhu, X., Miller, A. J., DeLuisi, J. J., Mateer, C. L., and Wuebbles, D. J.: Effects of auto-correlation and temporal sampling schemes on estimates of trends and spatial correlation, J. Geophys. Res., 95, $20507-$ 20 517, 1990.

Tung, K. K. and Yang, H.: Global QBO in circulation and ozone. Part I: Reexamination of observational evidence, J. Atmos. Sci., 51, 2699-2707, 1994.

Uppala, S. M., Källberg, P. W., Simmons, A. J., Andrae1, U., da Costa Bechtold, V., Fiorino, M., Gibson, J. K., Haseler, J., Hernandez, A., Kelly, G. A., Li, X., Onogi, K., Saarinen, S., Sokka, N., Allan, R. P., Andersson, E., Arpe, K., Balmaseda, M. A., Beljaars, A. C. M., van de Berg, L., Bidlot, J., Bormann, N., Caires, S., Chevallier, F., Dethof, A., Dragosavac, M., Fisher, M., Fuentes, M., Hagemann, S., Holm, E., Hoskins, B. J., Isaksen, L., Janssen, P. A. E. M., Jenne, R., McNally, A. P., Mahfouf, 
J., Morcrette, J., Rayner, N. A., Saunders, R. W., Simon, P., Sterl, A., Trenberth, K. E., Untch, A., Vasiljevic, D., Viterbo, P., and Woollen, J.: The ERA40 analysis, Quart. J. Roy. Meteorol. Soc., 131, 2961-3012, 2006.

Viereck, R., Puga, L., McMullin, D., Judge, D., Weber, M., and Tobiska, W. K.: The Mg II index: A proxy for solar EUV, Geophys. Res. Lett., 28, 1343-1346, 2001.

Viereck, R. A., Floyd, L., Crane, P., Woods, T., Knapp, B., Rottman, G., Weber, M., Puga, L., and DeLand, M.: A composite Mg II index spanning from 1978 to 2003, Space Weather, 30, S10005, doi:10.1029/2002GL016008, 2004.

Weatherhead, E. C., Reinsel, G. C., Tiao, G. C., Meng, X., Choi, D., Cheang, W., Keller, T., DeLuisi, J., Wuebbles, D. J., Kerr, J. B., Miller, A. J., Oltmans, S. J., and Frederick, J. E.: Factors affecting the detection of trends: Statistical considerations and applications to environmental data, J. Geophys. Res., 103, 17 149-17 162, 1998.

Weber, M., Dhomse, S., Wittrock, F., Richter, A., Sinnhuber, B., and Burrows, J. P.: Dynamical control of $\mathrm{NH}$ and $\mathrm{SH}$ winter/spring total ozone from GOME observations in 1995-2002, Geophys. Res. Lett., 30, 1583, doi:10.1029/2002GL016008, 2003.

Weber, M., Lamsal, L. N., Coldewey-Egbers, M., Bramstedt, K., and Burrows, J. P.: Pole-to-pole validation of GOME WFDOAS total ozone with groundbased data, Atmos. Chem. Phys., 5, 1341-1355, 2005.
WMO: Scientific Assessment of Ozone Depletion: 1998, Global Ozone Research and Monitoring Project Report 44, World Meteorological Organization, Geneva, http://www.wmo.ch/web/arep/ ozone.html, 1999.

WMO: Scientific Assessment of Ozone Depletion: 2002, Global Ozone Research and Monitoring Project Report 47, World Meteorological Organization, Geneva, http://www.wmo.ch/web/arep/ ozone.html, 2003.

Wohltmann, I., Rex, M., Brunner, D., and Mäder, J.: Integrated equivalent latitude as a proxy for dynamical changes in ozone column, Geophys. Res. Lett., 32, L09811, doi:10.1029/2005GL022497, 2005.

Yulaeva, E., Holton, J. R., and Wallace, J. M.: On the cause of the annual cycle in the tropical lower stratospheric temperature, J. Atmos. Sci., 51, 169-174, 1994.

Zerefos, C. S., Tourpali, K., Bojkov, R., Balis, D., Rognerund, B., and Isaksen, I.: Solar acticity - total ozone relationships: observations and model studies with heterogeneous chemistry, J. Geophys. Res., 102, 1561-1569, 1997.

Ziemke, J. R., Chandra, S., McPeters, R. D., and Newman, P. A.: Dynamical proxies of column ozone with applications to global trend models, J. Geophys. Res., 102, 6117-6129, 1997. 